\title{
Stabilisation of excavated slopes in strain-softening materials with piles
}

\author{
F. C. SUMMERSGILL*, S. KONTOE† and D. M. POTTS
}

\begin{abstract}
The use of a row of discrete vertical piles is an established method, successfully used to remediate failure of existing slopes and to stabilise potentially unstable slopes created by widening transport corridors. This paper challenges the assumptions made in current design procedures for these piles, which treat the pile only as an additional force or moment and simplify soil-pile interaction. Two-dimensional planestrain finite-element analyses were performed to simulate the excavation of a slope in a stiff clay and the interaction of vertical piles within the slope. A non-local strain-softening model was employed for the stiff clay to reduce the mesh dependency of the solution. An extensive parametric study was performed to systematically examine the impact of pile position, dimensions (length and diameter) and time of pile construction on the stability of a cutting in London Clay, which was chosen as a representative strainsoftening material. A variety of different failure mechanisms were identified, depending on pile location, dimensions and time of construction. The variability of the pile and slope interaction that was modelled suggests that an oversimplification during design could miss the critical failure mechanism or provide a conservative stabilisation solution. Given the prevalence of stiff clay slopes in the UK, increased capacity requirements of transport infrastructure and the age of slopes in this material, an informed and more realistic design of stabilisation piles will become increasingly necessary.
\end{abstract}

KEYWORDS: piles \& piling; slopes; soil stabilisation; strain

\section{INTRODUCTION}

The use of a row of discrete vertical piles is an established slope stabilisation method and has been successfully used to remediate failure of an existing slope or to stabilise potentially unstable slopes created by widening transport corridors (e.g. Smethurst \& Powrie, 2007; Ellis et al., 2010). A row of spaced piles provides added shear resistance to the movement of the soil by pinning the unstable and stable layers together and by transferring the bending moment caused by the movement of unstable soil to the underlying stable ground (Ellis et al., 2010). The resistance to the movement of the soil downslope is provided by a pile's shear strength and when there is a suitably spaced row of piles, by soil arching between the piles (Ito \& Matsui, 1975; Hassiotis et al., 1997).

The majority of the existing design procedures for horizontally loaded vertical stabilisation piles employ the displacements and/or critical slip surface of the unstabilised slope as the basis for the design of the stabilisation scheme. The $p-y$ method uses the expected soil displacements to calculate pile reaction (e.g. Baguelin et al., 1977; Lee et al., 1995; Georgiadis \& Georgiadis, 2010; Galli \& di Prisco, 2013). In a limit equilibrium (e.g. Hassiotis et al., 1997; Zhang \& Wang, 2010), limit analysis (e.g. Ausilio et al., 2001)

Manuscript received 10 April 2017; revised manuscript accepted 20 September 2017. Published online ahead of print 30 October 2017.

Discussion on this paper closes on 1 December 2018, for further details see p. ii.

Published with permission by the ICE under the CC-BY 4.0 license. (http://creativecommons.org/licenses/by/4.0/)

* Formerly Imperial College London; now Tony Gee \& Partners LLP, Esher, UK.

$\dagger$ Department of Civil \& Environmental Engineering, Imperial College London, London, UK (Orcid:0000-0002-8354-8762).

t Department of Civil \& Environmental Engineering, Imperial College London, London, UK. design procedure, the pile is treated only as an additional force or moment located where the critical slip surface and pile coincide. These methods as well as hybrid methods, which combine limit equilibrium with finite-element (FE) analysis (Kourkoulis et al., 2012), assume that the presence of a pile will not affect the failure mechanism.

Numerical methods (finite difference and FE) have also been used to model the pile and soil interaction in an unstable slope. The advantage of these methods is that they eliminate the requirement for a priori definition of the slip surface and therefore they do not predetermine the failure mechanism. The emphasis in previous numerical studies has been on soil arching between adjacent piles (Ellis et al., 2010), on verifying newly proposed simplified procedures (Georgiadis \& Georgiadis, 2010; Kourkoulis et al., 2012) or on comparison with existing method of analyses (Cai \& Ugai, 2000).

The interaction of the pile with the developing failure mechanism in slopes stabilised with piles has not been sufficiently investigated. The soil-pile interaction and the potential failure mechanism become more complicated in slopes excavated in stiff clays, which are widespread across the rail and road networks in the UK and in other parts of the world. It is well established that these slopes are prone to progressive failure (Potts et al., 1997), which can develop over several decades after their excavation/formation. In the present study, two-dimensional plane-strain FE analyses were performed to simulate the excavation of a slope in an overconsolidated stiff clay and the interaction of vertical piles within the slope. A non-local strain-softening model (Galavi \& Schweiger, 2010) was employed for the stiff clay to reduce the mesh dependency of the solution along with a coupled consolidation formulation, which facilitates the modelling of progressive failure. The parametric analyses examine the impact of pile position, dimensions (length and diameter), as well as time of pile construction on the stability of a cutting in stiff clay, challenging the assumptions made in current design procedures for these piles, that is treating the pile only as an additional force or moment and simplifying soil-pile interaction. 
DESCRIPTION OF THE NUMERICAL MODEL

Analysis arrangement and assumed ground conditions

An extensive parametric study was performed to systematically examine the impact of pile position, dimensions (length and diameter) and time of pile construction on the stability of a cutting in London Clay, which was chosen as a representative strain-softening material. The analyses are performed for a generic slope geometry with dimensions known to be unstable in London Clay without any stabilisation measures (Potts et al., 1997; Ellis \& O'Brien, 2007). The slope is $10 \mathrm{~m}$ high with a 1 in 3 vertical to horizontal slope angle. The adopted model represents one half of a symmetric excavation and the width of the cutting $(16 \mathrm{~m})$ is chosen to correspond to a typical two- to three-lane motorway. All the analyses were undertaken with the Imperial College FE program ICFEP (Potts \& Zdravković, 1999) in plane-strain conditions, adopting eight-noded isoparametric elements with reduced integration. An accelerated modified Newton-Raphson scheme with a substepping stress point algorithm was employed to solve the non-linear FE equations (Potts \& Zdravković, 1999). It should be noted that a coupled consolidation formulation is employed, which allows the modelling of the generation of excess pore fluid pressures during excavation and their subsequent equilibration with time. The mesh configuration was designed to model piles as beam elements in 26 potential locations and is shown in Fig. 1, together with the associated mechanical and hydraulic boundary conditions. The horizontal displacement was restricted on the vertical boundaries, while the bottom boundary was fixed in both horizontal and vertical directions. Before the excavation of the slope, initial stresses are specified in the soil using a bulk unit weight of $\gamma=18.8 \mathrm{kN} / \mathrm{m}^{3}$ and a uniform coefficient of lateral earth pressure, $K_{0}=2 \cdot 0$. The pore water pressures are hydro-static with $10 \mathrm{kPa}$ suction specified at the ground surface, following the average height expected for the phreatic surface in the UK (Vaughan \& Walbancke, 1973). The bottom and side boundaries are impermeable. The permeability, $k$, of the soil is modelled as isotropic and is linked to the mean effective stress, $p^{\prime}$, using the non-linear relationship in equation (1) (Vaughan, 1994).

$$
k=k_{0} \mathrm{e}^{-b p^{\prime}}
$$

The slope was excavated in horizontal layers over $0 \cdot 25$ years. This unloads the soil surrounding the excavation and the low permeability of the soil creates negative pore water pressures. After excavation, $10 \mathrm{kPa}$ suction is applied at the free boundary, as indicated in Fig. 1. Time and consolidation allow the excess pore water pressures to slowly dissipate. The changes in pore water pressures and strainsoftening behaviour of the stiff clay eventually lead to failure of the slope. The point of failure is defined as the last increment of the analysis that will converge with a time step of 0.01 years. Initially time steps of 1 year are employed and the size of the incremental step is reduced as slope failure is approached. The slope failure mechanism for each analysis was identified from the contours of accumulated plastic deviatoric strain and/or the incremental displacement vectors for the final converged increment of the analysis.

In addition to the previously described coupled consolidation analyses, where appropriate, factor of safety (FoS) analyses were also performed either immediately after excavation or at a set time post excavation. Potts \& Zdravković (2012) showed that the most consistent approach in computing the FoS in FE analysis is to start the analysis with the characteristic strength and at relevant stages of the analysis to gradually increase the safety factor until failure in the soil is fully mobilised. In each increment of the analysis a larger FoS is adopted until failure is reached. The FoS is applied by reducing the strength properties of the soil by a factor, $F$, as shown in equations (2) and (3)

$$
\begin{aligned}
& c^{\prime}=\frac{c_{\text {in }}^{\prime}}{F_{\mathrm{s}}} \\
& \phi^{\prime}=\tan ^{-1}\left(\frac{\tan \phi_{\text {in }}^{\prime}}{F_{\mathrm{s}}}\right)
\end{aligned}
$$

where $F_{\mathrm{s}}$ is the current FoS and $c_{\mathrm{in}}^{\prime}$ and $\phi_{\mathrm{in}}^{\prime}$ are the values of cohesion and angle of shearing resistance, respectively, at the beginning of the FoS analysis. In the present study the strength reduction started either once the excavation was completed or at a set time post excavation. The FoS was incrementally increased from an initial value of 1.0 until the factored strength resulted in an unstable slope. The time and associated pore pressure changes are stopped on the increment prior to the first FoS increment and the remaining FoS analysis is drained. In each increment of the analysis, it is the current strength that is factored and so when a strength has been reduced using a strain-softening model, the reduced strength is factored. The strain-softening behaviour is therefore still captured by the FoS analyses.

\section{Non-local strain-softening soil model}

The soil behaviour was simulated with a strain-softening variant of the Mohr-Coulomb model (Potts et al., 1990). This is an elasto-plastic model in which softening behaviour

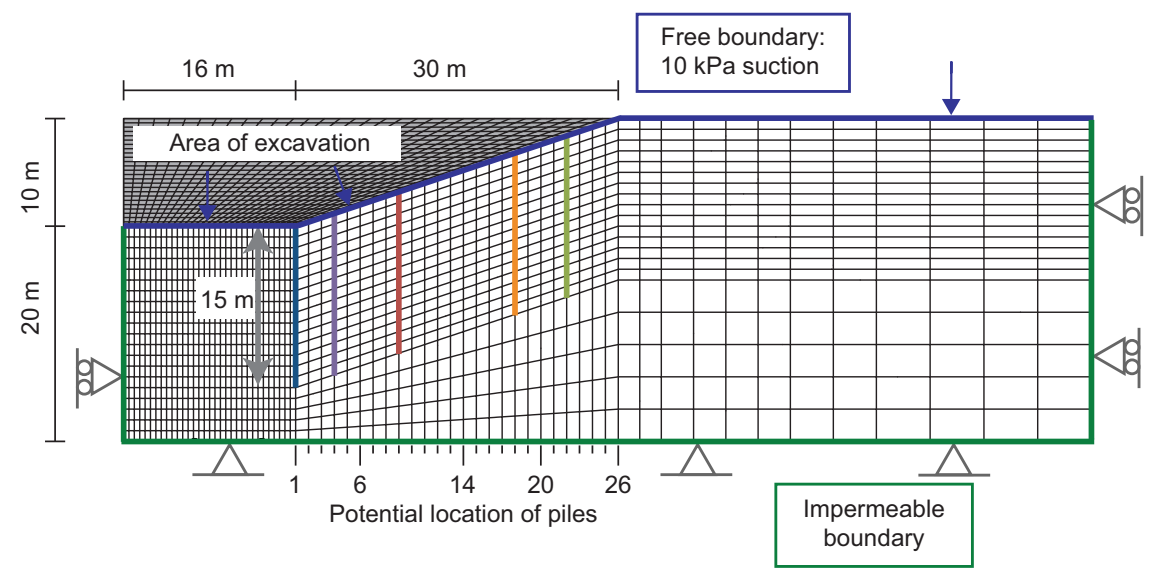

Fig. 1. FE mesh configuration with mechanical and hydraulic boundary conditions. A full-colour version of this figure can be found on the ICE Virtual Library (www.icevirtuallibrary.com) 
is facilitated through a variation of the angle of shearing resistance, $\phi^{\prime}$, and the cohesion intercept, $c^{\prime}$, with the deviatoric plastic strain invariant, as shown in Fig. 2(a). The limits for peak $\left(\phi_{\mathrm{p}}^{\prime}, c_{\mathrm{p}}^{\prime}\right)$ and residual $\left(\phi_{\mathrm{r}}^{\prime}, c_{\mathrm{r}}^{\prime}\right)$ strength are specified in the model by a percentage value of the deviatoric plastic strain invariant $\left(E_{\mathrm{dp}}^{\mathrm{p}}, E_{\mathrm{dr}}^{\mathrm{p}}\right.$, respectively) which is defined in equation (4)

$$
E_{\mathrm{d}}^{\mathrm{p}}=\frac{2}{\sqrt{6}} \sqrt{\left(\varepsilon_{\mathrm{p} 1}-\varepsilon_{\mathrm{p} 2}\right)^{2}+\left(\varepsilon_{\mathrm{p} 2}-\varepsilon_{\mathrm{p} 3}\right)^{2}+\left(\varepsilon_{\mathrm{p} 3}-\varepsilon_{\mathrm{p} 1}\right)^{2}}
$$

where $\varepsilon_{\mathrm{p} 1}, \varepsilon_{\mathrm{p} 2}, \varepsilon_{\mathrm{p} 3}$ are the principal plastic strains. The material properties are summarised in Table 1 and are based on the work of Kovacevic (1994) and Potts et al. (1997), who simulated a realistic failure time and mechanism that agreed with field data for cutting slopes of the same dimensions in London Clay. The adopted permeability values are from subsequent work of Hight et al. (2007). It is well established that the conventional FE solution of strain-softening problems, in which strain localisation occurs within a zone of limited thickness, can lead to numerical instability and significant mesh dependency of the solution (Galavi \& Schweiger, 2010; Summersgill et al., 2017a, 2017b). The non-local method (Eringen, 1981; Bazant \& Jirasek, 2002) alleviates these issues, adopting a distribution function that spreads the strain of the material at a point over a pre-defined surrounding volume. Recently Summersgill et al. (2017b) showed that the use of non-local regularisation in slope

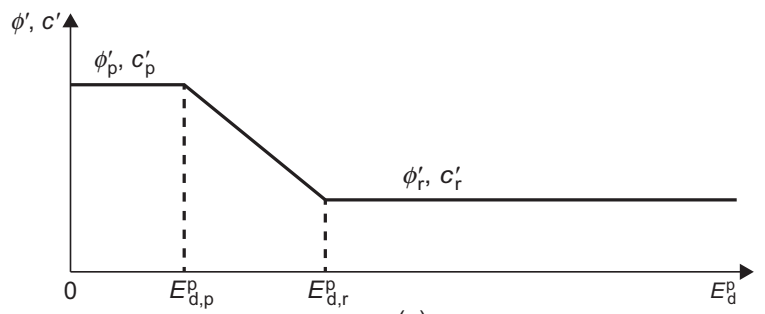

(a)

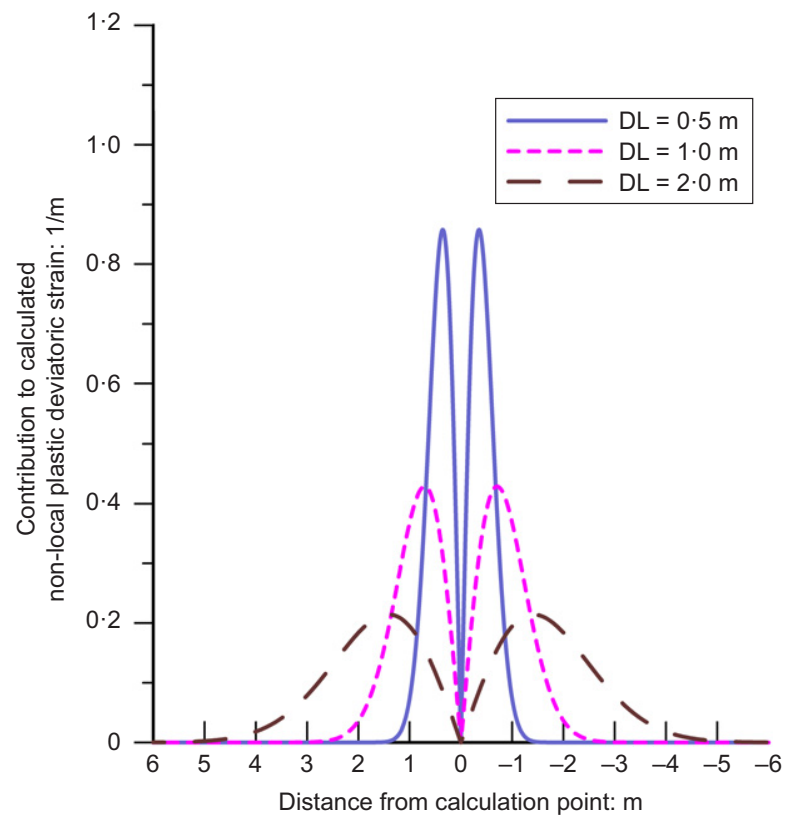

(b)

Fig. 2. (a) Variation of the angle of shearing resistance $\phi^{\prime}$ and the cohesion intercept $c^{\prime}$ with the deviatoric plastic invariant $E_{\mathrm{dp}}$ (adapted from Potts et al., 1990). (b) The impact of DL on the weighting function distribution
Table 1. Soil model parameters (Kovacevic, 1994; Potts et al., 1997; Hight et al., 2007)

\begin{tabular}{l|l}
\hline Property & Assumed value \\
\hline Bulk unit weight, $\gamma$ & $18 \cdot 8 \mathrm{kN} / \mathrm{m}^{3}$ \\
Peak strength (bulk) & $c_{\mathrm{p}}^{\prime}=7 \mathrm{kPa}, \phi_{\mathrm{p}}^{\prime}=20^{\circ}$ \\
Residual strength & $c_{\mathrm{r}}^{\prime}=2 \mathrm{kPa}, \phi_{\mathrm{r}}^{\prime}=13^{\circ}$ \\
Poisson ratio, $\mu$ & $0 \cdot 2$ \\
Angle of dilation, $\psi$ & $0^{\circ}$ \\
Young's modulus, $E$ & $25\left(p^{\prime}+100\right)(\mathrm{min} 4000 \mathrm{kPa})$ \\
Plastic deviatoric strain, $E_{\mathrm{d}}$ & Peak $5 \%, \mathrm{residual} 20 \%$ \\
Coefficient of permeability, $k$ & $k_{0}=5 \times 10^{-10} \mathrm{~m} / \mathrm{s}$ \\
& $b=0 \cdot 003 \mathrm{~m}^{2} / \mathrm{kN}$ \\
\hline
\end{tabular}

stability problems reduces significantly the mesh dependency and leads to consistent failure mechanisms irrespective of the adopted element size. Therefore, in this study the non-local regularisation approach of Galavi \& Schweiger (2010) (G\&S) is employed to limit the mesh dependency of the strainsoftening calculations. The non-local plastic strain, which regulates the reduction in strength, is given by equation (5) as proposed by Eringen (1981) and Bazant et al. (1984).

$$
\boldsymbol{\varepsilon}^{\mathrm{p} *}\left(x_{n}\right)=\frac{1}{V_{\omega}} \iiint\left(\omega\left(x_{n}^{\prime}\right) \boldsymbol{\varepsilon}^{\mathrm{p}}\left(x_{n}^{\prime}\right)\right) \mathrm{d} x_{1}^{\prime} \mathrm{d} x_{2}^{\prime} \mathrm{d} x_{3}^{\prime}
$$

where $\varepsilon^{\mathrm{p}}$ is the accumulated plastic deviatoric strain tensor, * denotes the non-local parameter, $x_{n}$ is the global coordinate at which the calculation of the non-local plastic strain, $\boldsymbol{\varepsilon}^{\mathrm{p} *}$ is required, whereas $x_{n}^{\prime}$ refers to all the surrounding locations, that is the location of reference strain, with $n=1,2,3$. Therefore, $\boldsymbol{\varepsilon}^{\mathrm{p}}\left(x_{n}^{\prime}\right)$ equals the reference (i.e. local) strain at the reference location. It should be noted the deviatoric plastic strain invariant in equation (4) is calculated based on $\boldsymbol{\varepsilon}^{\mathrm{p} *}$. The weighting function, $\omega\left(x_{n}^{\prime}\right)$ is defined for all the reference locations, but it is centred at the location $x_{n}$. The G\&S method adopts a weighting function (see equation (6)) which limits the central concentration of strains, assuming that the development of the slip surface is influenced by the directly surrounding areas and not by the concentrated strain at the centre of the slip surface.

$$
\omega\left(x_{n}^{\prime}\right)=\frac{\sqrt{\left(x_{n}^{\prime}-x_{n}\right)^{\mathrm{T}}\left(x_{n}^{\prime}-x_{n}\right)}}{\mathrm{DL}^{2}} \exp \left[-\frac{\left(x_{n}^{\prime}-x_{n}\right)^{\mathrm{T}}\left(x_{n}^{\prime}-x_{n}\right)}{\mathrm{DL}^{2}}\right]
$$

where DL is the defined length for non-local strain calculation. The integral of the weighting function in the three dimensions $x_{1}, x_{2}$ and $x_{3}$ is referred to as the reference volume, $V_{\omega}$, as shown in equation (7). This is used to normalise the calculation of the non-local strain and for the G\&S distribution is equal to approximately one. The latter attribute of the function ensures that a uniform field of strain would remain unmodified. The defined length, DL, influences the distribution of the weighting function as shown in Fig. 2(b). A higher DL is expected to result in a wider slip surface with a lower maximum non-local strain. This affects the rate of strain softening, as the same input of local strain will result in a lower non-local strain for a larger defined length and therefore a slower rate of softening.

$$
V_{\omega}=\iiint \omega\left(x_{n}^{\prime}\right) \mathrm{d} x_{1}^{\prime} \mathrm{d} x_{2}^{\prime} \mathrm{d} x_{3}^{\prime}
$$

In all the analyses presented herein a DL $=1 \mathrm{~m}$ was used, which in conjunction with the peak and residual strength deviatoric plastic strain limits of $5 \%$ and $20 \%$, respectively (see Table 1), leads to a representative softening rate for 
London Clay as demonstrated by Summersgill et al. (2017b). The selection of DL in granular materials is normally related to the mean grain size. For example, Galavi \& Schweiger (2010) suggest DL to be 10-20 times the mean grain diameter in dense sands. However, for boundary value problems in FE analysis, and in particular in clay materials, such a correlation with the mean grain size becomes impractical, as the element size in any direction should be at most equal to DL for the non-local calculation to be effective. Therefore in agreement with Galavi \& Schweiger (2010) the selection of DL can be based on the softening rate, although this might result in unrealistically large shear band thickness. An additional non-local parameter, the radius of influence, was also used to restrict the area of the reference space for the non-local calculations and therefore increase numerical efficiency. The radius of influence was set at three multiples of DL (i.e. $3 \mathrm{~m}$ ) based on the recommendations of Summersgill et al. (2017b), who found this ratio to be a suitable compromise between accuracy and time saving.

\section{Pile simulation}

In order to systematically examine the impact of the pile position and dimensions (length and diameter) the mesh was designed to allow the placement of vertical piles in 26 different locations between the toe and crest of the slope (Fig. 1), while the length of the pile can be varied at $1 \mathrm{~m}$ intervals up to $15 \mathrm{~m}$. In the analyses the pile is 'wished in place', either immediately after excavation of the slope or at some subsequent time when the time of pile construction is examined, employing a single column of beam elements placed between the solid quadrilateral elements. These elements model the bending and shear behaviour of the pile using the specified stiffness, density, cross-sectional area, $A$, and second moment of area, $I$. The pile is assumed to be connected to the adjacent soil, as interface elements were not employed in the analyses. The simulated pile diameter is $0.9 \mathrm{~m}$ (unless parametrically varied) with a spacing of $2.7 \mathrm{~m}$ or three diameters. The selection of pile spacing follows the recommendations of previous studies which demonstrated that pile spacing should be a distance from centre to centre between three and five pile diameters to reduce soil flow between piles (Hayward et al., 2000; Carder, 2005; Kourkoulis et al., 2011). Since the piles are simulated in two-dimensional (2D) plane strain conditions, the calculated area $A$ and second moment of area $I$ were divided by the pile spacing to account for the total quantity of soil that would be supported by a discrete pile in a row. This $2 \mathrm{D}$ simulation does not model the behaviour of soil between the piles; consequently the contribution of arching or soil flow between piles is not directly considered. However, the pile spacing selected means it is likely that soil arching would take place and therefore soil would not flow between the piles and its load would be transferred into the piles.

The pile is modelled as a linear elastic material with the properties listed in Table 2 and the maximum bending moment, axial and shear forces were monitored throughout the analysis to identify potential plastic hinge formation. It

Table 2. Pile material properties

\begin{tabular}{l|l}
\hline Property for beam element & Value employed \\
\hline Material density, $\rho$ & $2 \cdot 4 \mathrm{Mg} / \mathrm{m}^{3}$ \\
Young's modulus, $E$ & $14 \times 10^{6} \mathrm{kPa}$ \\
Poisson ratio, $\mu$ & $0 \cdot 15$ \\
Shear correction factor, $\kappa$ & $0 \cdot 8333$ \\
\hline
\end{tabular}

should be noted that a Young's modulus value of 14 GPa was adopted, which is lower than the typical compressive value $(25 \mathrm{GPa})$ for concrete given by the British Standards Institute (Higgins et al., 2013). A stabilising pile is subjected to tensile stresses due to soil movements which, according to Durrani (2006), cause the concrete to form micro-cracks, reducing its flexural rigidity by two to three times, justifying the use of a lower Young's modulus value. The shear correction factor, $\kappa$, is used to account for the shear stress changes across the area of the pile, and a value of $\kappa$ equal to 0.8333 was adopted (Potts \& Zdravković, 2001). Finally, no restraint of the pile is provided at the ground surface and the corresponding bending moment is always zero; therefore the impact of a potential capping beam was not considered.

\section{DESIGN PARAMETERS AFFECTING SLOPE STABILISATION WITH PILES \\ The influence of pile location}

The position of a vertical pile row between the crest and toe of a slope is expected to have a significant impact on the development of a potential failure mechanism and as a consequence a varied contribution to slope stabilisation. To investigate this aspect, a $15 \mathrm{~m}$ long pile was placed immediately after excavation in each of the 26 locations, which are spaced $1.2 \mathrm{~m}$ apart, between the toe and crest of the slope, as indicated in Fig. 1. Fig. 3 plots the horizontal displacement variation of the mid-slope ground surface point with time to failure for five representative pile positions, as well as for the slope without piles. The corresponding plot with the response for all 26 pile analyses is included in the Appendix. The results show that the presence of the pile row did not prevent failure, but it did extend the lifetime of the slope (which is 40 years without piles), resulting in failure times ranging from 37 years to 224 years. Looking more closely at the results, five distinct failure mechanisms were identified by the pattern of slope and pile movements. An example of each failure mechanism is given in Fig. 4 in terms of contours of accumulated plastic deviatoric strain and in Fig. 5 in terms of vectors of incremental displacement for the final converged increment of the analysis. The corresponding plots for all 26 analyses are also given in the Appendix. It should be noted that the sizes of the arrows in the plots of vectors of incremental displacements are relative to the largest incremental displacement for each analysis, but not proportional between the analyses due to the large difference in the size of displacements depending on the mechanism. The positions of the five analyses shown in Figs 4 and 5 are identified in Fig. 1 by the thicker vertical (coloured) lines. The numbers in Fig. 1 identify the last pile position for each mechanism type. The identified mechanisms have been grouped as follows

(a) mechanism 1 corresponds to position 1 only

(b) mechanism 2 corresponds to positions 2 to 6

(c) mechanism 3 corresponds to positions 7 to 14

(d) mechanism 4 corresponds to positions 15 to 20

(e) mechanism 5 corresponds to positions 21 to 26 .

In two of the identified mechanisms, mechanisms 1 (Figs 4(b) and 5(b)) and 5 (Figs 4(f) and 5(f)), the pile does not intercept the slip surface. In mechanism 1, with a pile at the very toe of the slope, failure occurred above the pile and the time to failure was actually 3 years less than for a slope without a pile (see Fig. 3). The presence of the pile suppresses the soil movements at the toe of the slope, concentrating soil movement into a single slip surface starting at the toe (see Fig. 4(b)). On the other hand, in the 


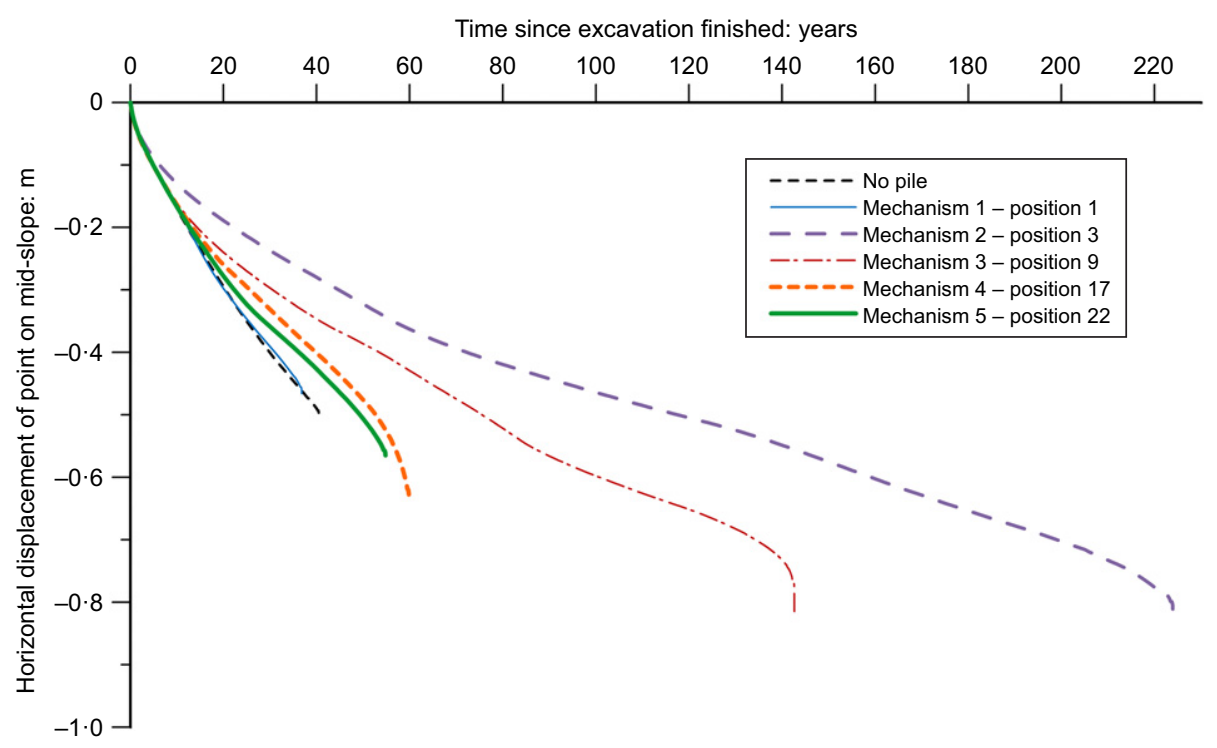

Fig. 3. Horizontal displacement variation of a mid-slope ground surface point over time for no-pile analysis and an example for each mechanism of pile and slope failure for $15 \mathrm{~m}$ long, $0.9 \mathrm{~m}$ dia. piles

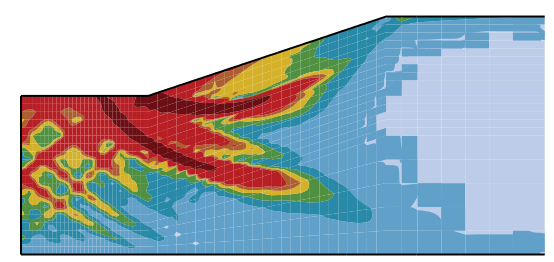

(a)

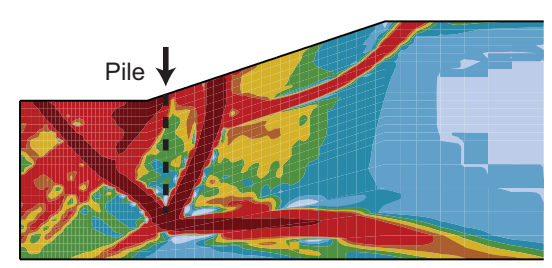

(c)

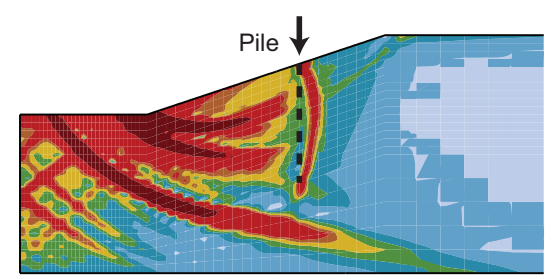

(e)

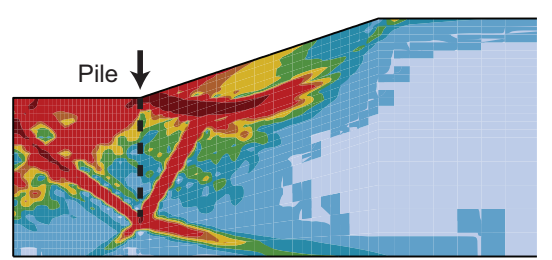

(b)

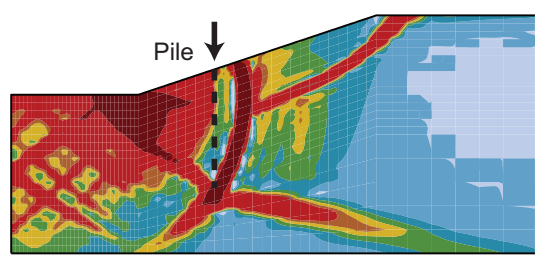

(d)

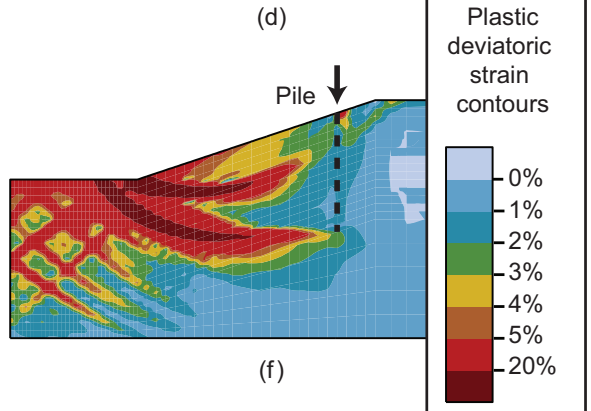

Fig. 4. Accumulated local plastic deviatoric strain contours for (a) no-pile analysis and (b)-(f) an example for each mechanism of pile and slope failure depending on pile location for $15 \mathrm{~m}$ long, $\mathbf{0 . 9} \mathrm{m}$ dia. piles: (b) mechanism 1 - position 1; (c) mechanism 2 - position 3 ; (d) mechanism 3 position 9; (e) mechanism 4 - position 17; (f) mechanism 5 - position 22 . A full-colour version of this figure can be found on the ICE Virtual Library (www.icevirtuallibrary.com)

no-pile analysis the development of a second slip surface below the toe (see Fig. 4(a)) is possibly the reason for the slightly slower slope failure, while the main critical slip surface (with strains exceeding 20\%) is practically the same in both cases resulting in similar time to failure. In mechanism 5 (Figs 4(f) and 5(f)), the failure of the slope downslope of the pile, without pile interaction, provides a modest increase in time to failure of 5 to 23 years. The pile effectively reduces the height of the slope by up to $2.4 \mathrm{~m}$, but sufficient height remains for failure of the slope to occur without the contribution of the mass behind the pile to increase the destabilising force.

In mechanism 4 the pile did interact to some extent with the failure mechanism and was subjected to horizontal displacements, as it can be seen by the horizontal arrows at the location of the pile and smaller movements of the soil 


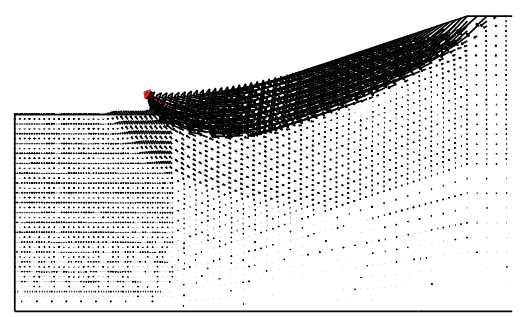

(a)

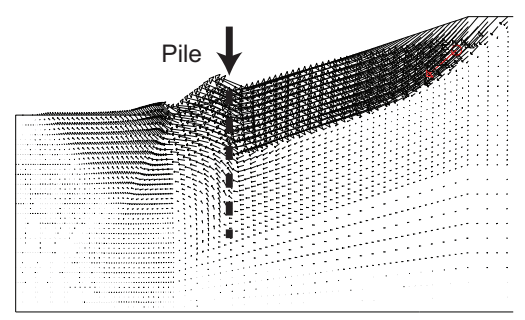

(c)

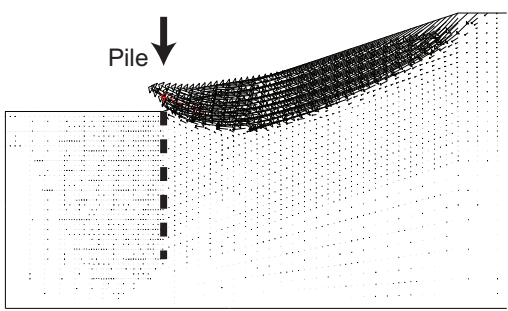

(b)

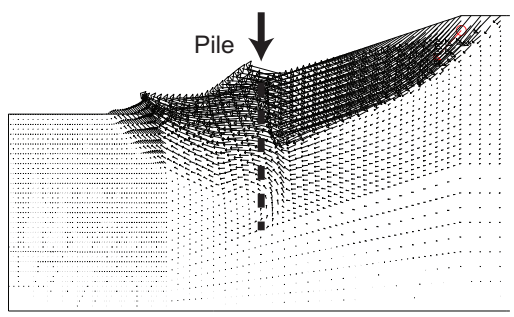

(d)

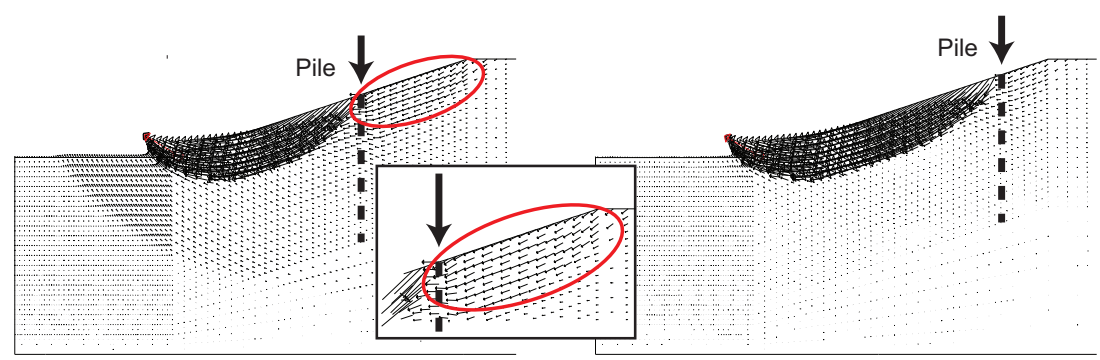

(e)

(f)

Fig. 5. Incremental displacement vectors for the final increment for (a) no-pile analysis and (b)-(f) an example for each mechanism of pile and slope failure depending on pile location for $15 \mathrm{~m}$ long, $0.9 \mathrm{~m}$ dia. piles: (b) mechanism 1 - position 1; (c) mechanism 2 - position 3; (d) mechanism 3 - position 9; (e) mechanism 4 - position 17; (f) mechanism 5 - position 22

upslope, Fig. 5(e). This resulted in an increase in the time to failure from 40 years (no piles) to between 57 and 98 years after excavation. However, this is still likely to be an inadequate improvement in stability for the required lifetime of transport slopes.

The most significant improvement in time to failure is seen in mechanisms 2 (Figs 4(c) and 5(c)) and 3 (Figs 4(d) and 5(d)), with ranges of 203-224 and 120-163 years, respectively, prior to slope failure. The movement of the pile in these analyses is an integral part of the failure mechanism. The pile movement occurs due to the force from the soil upslope or the movement of soil downslope reducing support in front of the pile. The pile in mechanism 2 undergoes similar horizontal displacement to mechanism 3 , but is subjected to larger vertical movements. The strain contours for this mechanism show large strains along two intersecting surfaces forming a deep-seated ' $v$ '-shaped slip surface beneath the base of the pile, with developed strains in excess of $20 \%$. The vertical movement of the pile is facilitated and indicated by the concentration of strains on these two surfaces. The ' $v$ ' shape had also begun to form for mechanism 1 (Fig. 4(b)), but the strain was far less than $20 \%$ and the shallow slip surface had developed preferentially.

The values of time to failure and FoS for each of the 26 pile locations are compared in Fig. 6. The FoS is evaluated 30 years after excavation, as Summersgill (2015) showed 30 years to be sufficient consolidation period for these slope dimensions to produce the same failure mechanism for the FoS and consolidation until failure analyses. The results generally cluster into the previously identified five

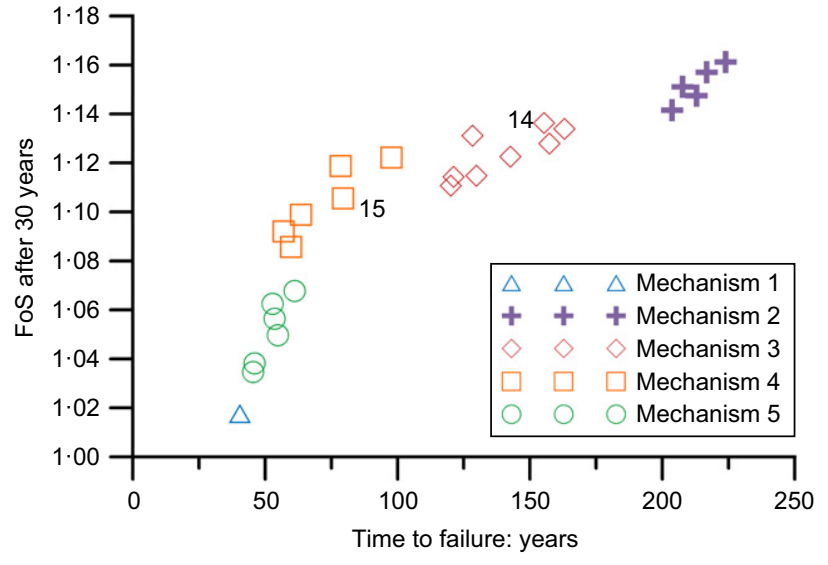

Fig. 6. Relationship between the time to failure and FoS for analyses with consolidation to completion and FoS evaluated after 30 years of consolidation, respectively

mechanisms of sequential pile positions. There is a similar range of times to failure within each mechanism and the corresponding FoS values create a trend distinct to each group.

The grouping of positions 2 to 6 within mechanism 2 is easy to identify in Fig. 6, with the magnitude of time and FoS values showing consistent variations and the highest FoS increase. It is, however, more difficult to distinguish between the groups for mechanisms 3 to 5. For example the time and 
FoS value for position 14 are much higher than the neighbouring positions and in particular position 15 . This indicates there may be a transition zone with the development of more than one potential failure mechanism. The magnitude of FoS results of mechanisms 4 and 5 may help to differentiate the two groups, but the times to failure are not significantly different spanning mechanism 4 and 5 . Overall the FoS predictions confirm that mechanisms 2 and 3 offer the most significant improvement in stability, whereas mechanisms 1 and 5 offer either zero or minimal improvement.

Figure 7 shows the bending moment distribution at the last converged increment for a representative pile position of each mechanism, while the corresponding plot with all the 26 analyses is included in the Appendix. The bending moment distributions confirm the limited pile interaction in mechanisms 1, 4 and 5, as the bending moment values are relatively low, particularly for mechanism 5 . As expected, the highest bending moments are predicted for mechanisms 2 and 3 , in which the pile presence dominates the development of the slip surface. For all cases, however, the predicted bending moments are well below the bending moment pile capacity for the considered pile dimensions, assuming adequate reinforcement, which is estimated to be $2584 \mathrm{kNm}$ (Summersgill, 2015).

It is also interesting to note the evolution of the bending moment distribution with time for mechanism 2 (position 3 ) depicted in Fig. 8. The 20 to 80 year period corresponds to a negative bending moment distribution with a single stationary point, caused by the larger relative horizontal movements

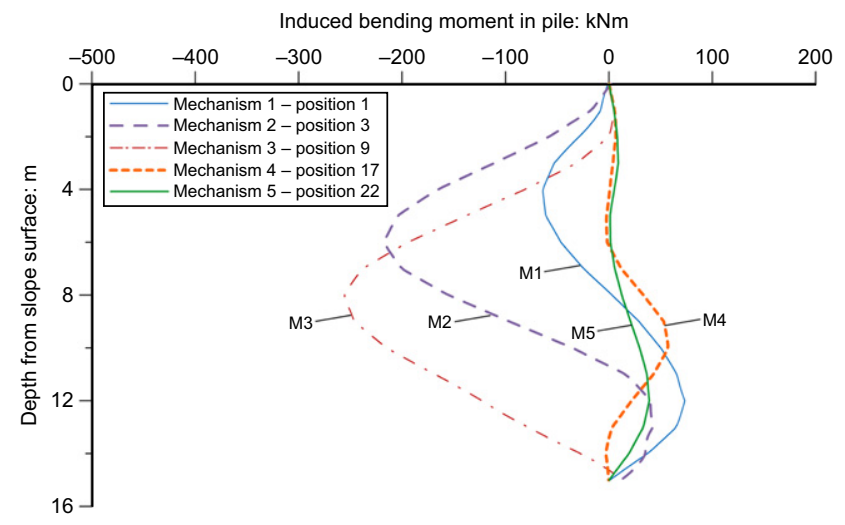

Fig. 7. The effect of pile position between the toe and crest of the slope on the bending moment induced in the $15 \mathrm{~m}$ long, $0.9 \mathrm{~m}$ dia. pile at the end of the analysis for each mechanism

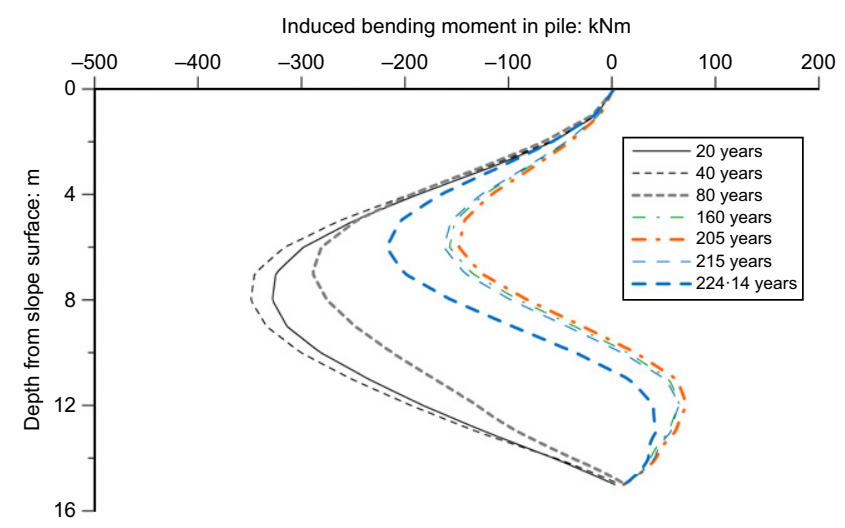

Fig. 8. The variation of bending moment of pile over time for analysis with a pile in position 3 , illustrating the behaviour of the pile for mechanism 2 at the top of the pile. After 80 years, the base of the pile then begins to move laterally as well as vertically, corresponding to the formation of a positive bending moment in the lower half of the pile and a reduction in the absolute value of the negative bending moment of the top half of the pile. This behaviour could be explained by the vertical movement of the base wedge of soil, caused by the horizontal movement of the upslope soil into the excavation. At failure the positive bending moment decreases and the absolute value of the negative bending moment increases, indicating an increased pressure from the movement of the soil upslope of the pile.

Overall, for the examined cases, it can be concluded that the presence of the pile does not prevent soil movement, which occurs as a reaction to slope excavation and high initial lateral soil stresses. The pile is most effective when it interacts with the development of the slip surface and affects the failure mechanism. This raises an obvious question about the suitability of limit equilibrium based design approaches which assume that the failure mechanism is not modified by the presence of the piles. Furthermore, it should be noted that in the present study the optimum pile location is close to the toe, and that the associated delay in the development of the failure mechanism for such pile locations can be attributed to the modelling of the strain softening. This has been confirmed by subsequent analyses of the same model dimensions in a non-softening material (Lee, 2015, not shown herein for brevity), which indicate an optimum pile position in the middle of the slope in agreement with previous studies.

\section{The influence of pile dimensions}

The relative positions of the base of the piles and the slip surfaces can affect the interaction of the pile in the slope. When the pile interrupts the development of a slip surface it forces an alternative failure mechanism to form. The presence of a pile may also modify the existing failure mechanism, improving or reducing stability. Furthermore, the diameter of the pile, as well as changing the dimension of the structure, changes the flexibility of the pile. As seen in the previous section, the piles are subjected to significant movement and induced bending moments and therefore the flexibility of the pile is likely to be an influential aspect of the pile-soil interaction. Therefore both these aspects, pile length and pile diameter, are examined sequentially in this section.

First, for a pile in position 9 (mechanism 3 ) the pile length was varied from $3 \mathrm{~m}$ to $12 \mathrm{~m}$ at $3 \mathrm{~m}$ intervals. The pile length investigation results are shown in Figs 9-11 together with the

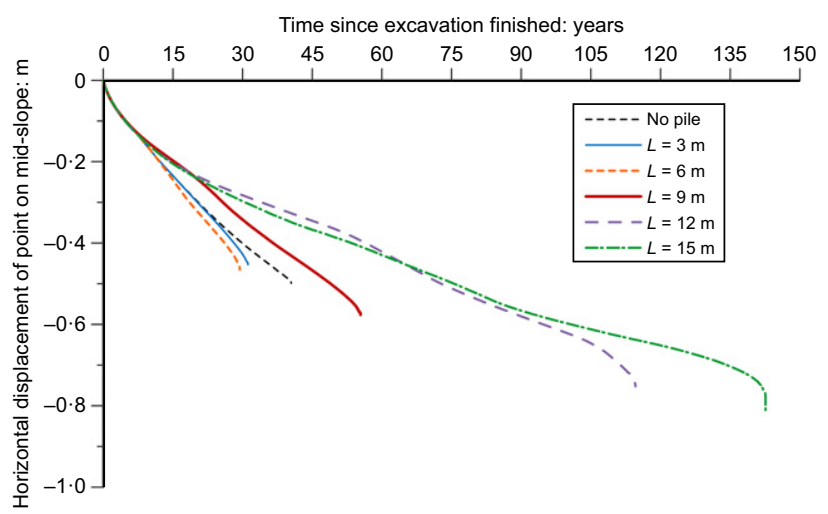

Fig. 9. Comparing the horizontal displacement of the mid-slope over time for analyses with varying pile lengths with a diameter of $0.9 \mathrm{~m}$ and in position 9 between the crest and toe of the slope 


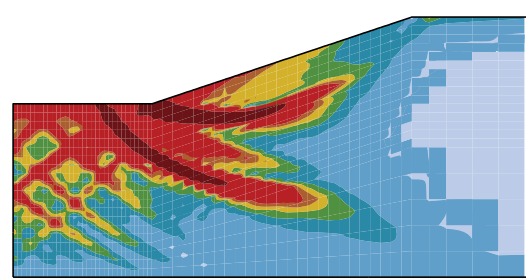

(a)

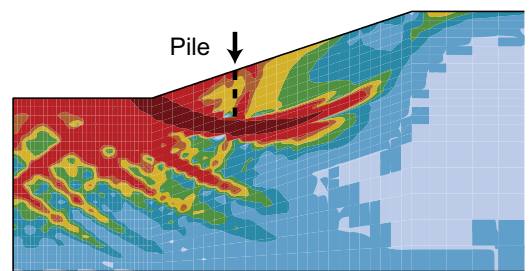

(c)

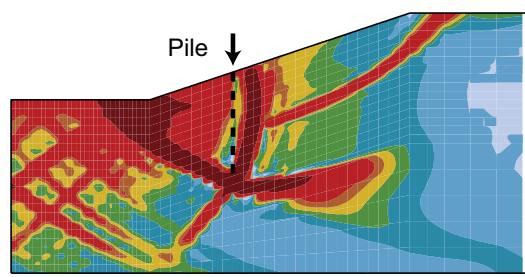

(e)

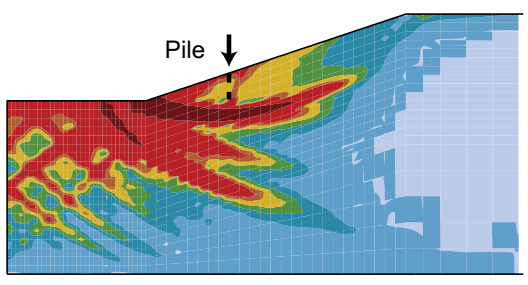

(b)

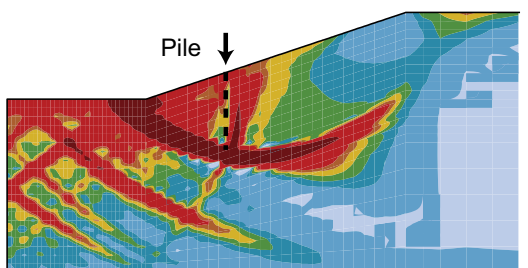

(d)

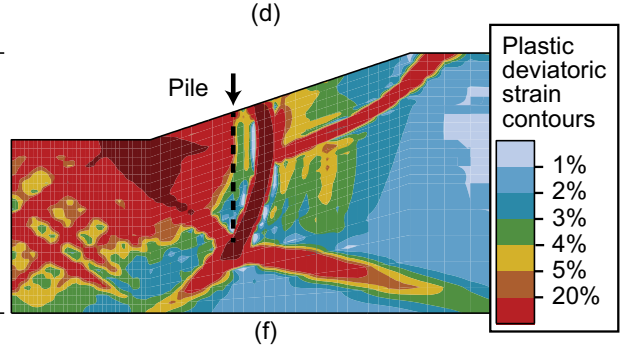

Fig. 10. Accumulated local plastic deviatoric strain contours for the final increment of analyses with a variation in pile length of a $0 \cdot 9 \mathrm{~m}$ dia. pile in position 9: (a) no pile; (b) length =3 m; (c) length = $6 \mathrm{~m}$; (d) length =9 m; (e) length = $12 \mathrm{~m}$; (f) length = $15 \mathrm{~m}$. A full-colour version of this figure can be found on the ICE Virtual Library (www.icevirtuallibrary.com)

Induced bending moment in pile: $\mathrm{kNm}$

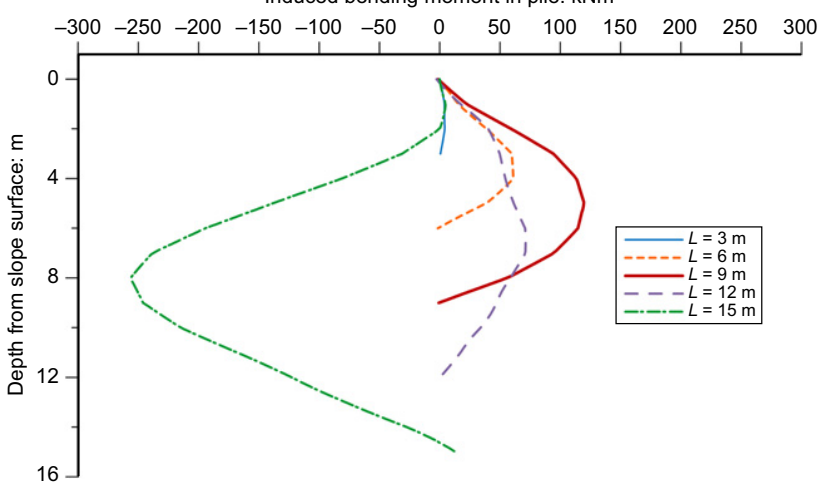

Fig. 11. The effect of pile length on the bending moment induced in the pile during the last increment of the analyses for piles of a varied length, a diameter of $0.9 \mathrm{~m}$ and in position 9 between the toe and crest of the slope

$15 \mathrm{~m}$ pile results for reference (the latter ones being identical to the ones presented in the previous section).

The plot of the horizontal displacement of the mid-slope surface point with time to failure (Fig. 9) shows that constructing a pile $3 \mathrm{~m}$ or $6 \mathrm{~m}$ in length immediately after excavation actually reduced the stability of the slope by a quarter compared to not constructing a pile. A $3 \mathrm{~m}$ pile does not intersect the shallow slip surface, whereas a $6 \mathrm{~m}$ pile barely intersects this surface (Figs 10(b) and 10(c)). In both these cases the critical slip surface forms beneath the base of the pile, translating it within the unstable mass. Furthermore, the non-critical slip surfaces have not developed to the same extent as the no-pile analysis and the time to failure of the slope has been reduced, indicating that the presence of the pile has encouraged preferential development of the shallowest slip surface. The development of the secondary slip surfaces is important, as they contribute to a delay in the time to failure, which was seen in several cases in this study. The $9 \mathrm{~m}$ long pile (Fig. 10(d)) provides some improvement in the time to slope failure by forcing an increase in depth of the critical slip surface (see contours for no-pile analysis in Fig. 10(a)), but the slip surface still passes beneath the pile and therefore the pile is again translated horizontally within the unstable mass. The shape of the bending moment variation with depth at the last converged increment of the analysis is very similar for these three pile lengths (i.e. $3 \mathrm{~m}$, $6 \mathrm{~m}$ and $9 \mathrm{~m}$ ) (Fig. 11), corroborating the development of an analogous overall failure mechanism.

In contrast, with a $12 \mathrm{~m}$ pile, a mechanically viable slip surface cannot form underneath the pile. The slip surface formed downslope of the pile and pressure from the soil behind the pile eventually caused sufficient bending of the pile for a slip surface to form upslope (Fig. 10(e)). This requires a longer period for development, extending the stability of the slope to 115 years (Fig. 9). The further increase in pile length to $15 \mathrm{~m}$ requires even more time for failure to occur. This is likely to be attributable to the reduced movements downslope of the pile because the base of the $15 \mathrm{~m}$ pile is too deep to interact with soil movement at the toe of the slope in the same way as the $12 \mathrm{~m}$ pile, Figs 10(e) and 10(f). It should be noted that the impact of pile length discussed here is only valid for position 9 in the slope, with less than $10 \mathrm{~m}$ of soil below the base of the pile. It would be expected for the impact of pile length to vary with location and depth to bedrock, reflecting the changing interaction of the pile and mechanically viable slip surfaces. However, the same conclusion would be anticipated, the pile must be extended past the depth of the potentially critical slip surfaces in order to provide a stabilising action. Once longer than the depth of the slip surface, an increase in pile length would extend the stability of the slope, but the stabilising effect would not increase linearly.

The diameter is also expected to affect the behaviour of the pile and therefore the mechanism of pile to soil interaction could be affected. The effects of pile diameter are investigated 
for a $15 \mathrm{~m}$ long pile in each of the three mechanisms previously identified as providing significant improvement in slope stability. The chosen pile positions between the toe and crest of the slope are positions 3, 9 and 17, which are a horizontal distance from the toe of the slope of $2.4 \mathrm{~m}, 9.6 \mathrm{~m}$ and $19 \cdot 2 \mathrm{~m}$, respectively. For each position, four diameters in addition to $0.9 \mathrm{~m}$ are examined: $0.6 \mathrm{~m}, 1.2 \mathrm{~m}, 1.5 \mathrm{~m}$ and $1.8 \mathrm{~m}$ (see Table 3). The diameter is used to calculate the area, $A$, and the second moment area, $I$, values, which are specified as properties for the beam elements used to model the piles. The $A$ and $I$ values are normalised by the spacing value and are therefore reliant on it (see Table 3 ). This is maintained at a ratio of three diameters in the presented results and therefore the actual value for spacing changes as the diameter value changes.

Figure 12 plots the horizontal displacement variation with time for the mid-slope surface point showing that an increase in pile diameter does not always increase the contribution to the stabilisation of the slope. For the three positions investigated, a larger and therefore stiffer pile with $1.5 \mathrm{~m}$ or $1.8 \mathrm{~m}$ dia. provided less stability than a $0.9 \mathrm{~m}$ dia. pile. These

Table 3. Parameters for the pile diameter investigation

\begin{tabular}{l|c|c|c}
\hline $\begin{array}{l}\text { Pile } \\
\text { diameter, } \\
d: \mathrm{m}\end{array}$ & $\begin{array}{c}\text { Pile } \\
\text { spacing, } \\
s: \mathrm{m}\end{array}$ & $\begin{array}{c}\text { Normalised } \\
\text { cross-sectional } \\
\text { area, } A: \mathrm{m}\end{array}$ & $\begin{array}{c}\text { Normalised } \\
\text { second moment } \\
\text { of area, } I: \mathrm{m}^{3}\end{array}$ \\
\hline 0.6 & $1 \cdot 8$ & $0 \cdot 1570796$ & $0 \cdot 0035343$ \\
$0 \cdot 9$ & $2 \cdot 7$ & 0.23562 & $0 \cdot 011928$ \\
1.2 & $3 \cdot 6$ & $0 \cdot 3141593$ & $0 \cdot 0282743$ \\
1.5 & $4 \cdot 5$ & 0.3926991 & $0 \cdot 0552233$ \\
1.8 & $5 \cdot 4$ & 0.4712389 & $0 \cdot 0954259$ \\
\hline
\end{tabular}

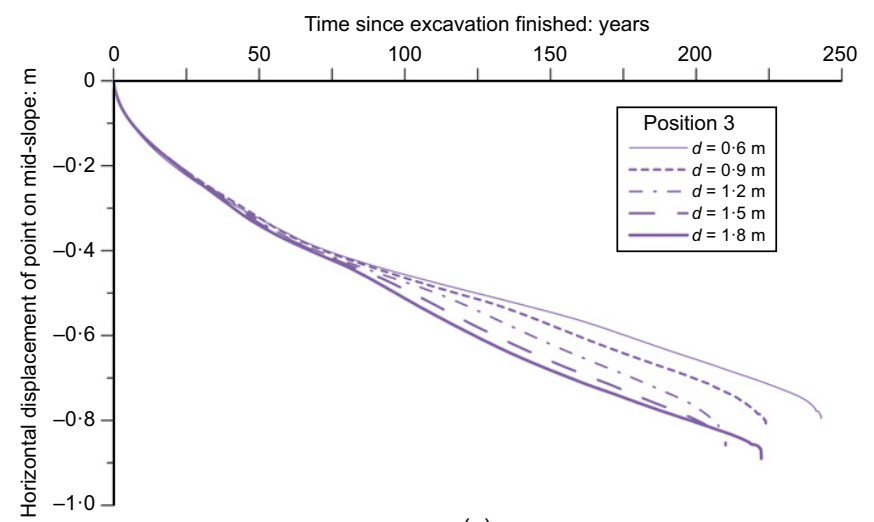

(a)

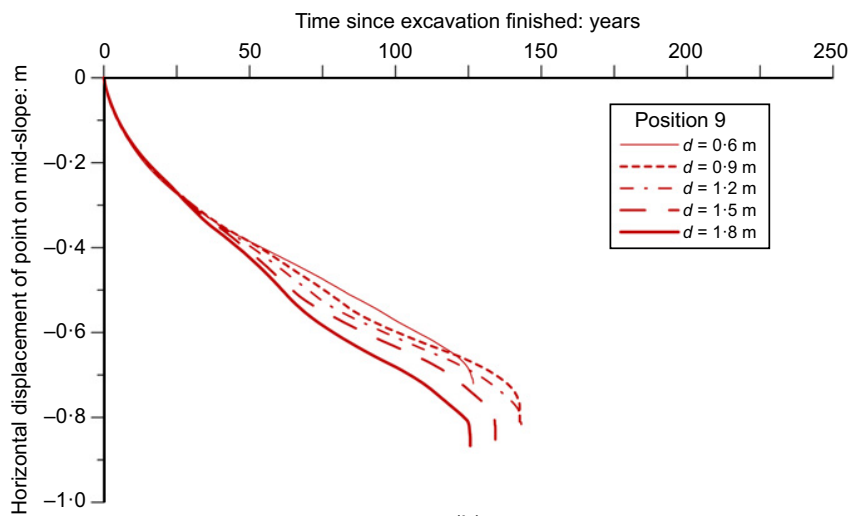

(b) larger piles were modelled as stabilising a larger volume of soil because the diameter to spacing ratio of 3 was maintained, while there was a variation in the comparable real value of pile spacing. The change in real spacing modelled provides useful information on the impact of pile flexibility and in exploring the sensitivity of the contribution of the pile to slope stabilisation with the variation of the two parameters, $A$ and $I$, that model pile stiffness in a $2 \mathrm{D}$ beam element. It should be noted that additional analyses in which the pile diameter was changed with a constant spacing maintained instead of constant ratio (not shown herein for brevity) showed the same patterns. This demonstrates that it is not just the volume of the stabilised soil that is important as the pile stiffness affects the interaction with the critical slip surface.

\section{Time of pile construction}

In all the analyses presented so far the pile is constructed immediately after slope excavation. This models the situation of employing piles as a preventative measure to extend the stability period of the slope if the design dimensions make the slope vulnerable to progressive failure. If the pile stabilisation system is used to remediate an existing slope that has been identified as unstable, then, in the case of a stiff clay cutting, the pile will be placed possibly decades after excavation. The time of pile construction can play a significant role in the effectiveness of the stabilisation and is examined parametrically herein by constructing the pile at different periods of $10,20,30$ and 40 years after slope excavation.

The $15 \mathrm{~m}$ long $0.9 \mathrm{~m}$ dia. pile is constructed using beam elements that are wished in place between the solid elements in position 9, 9.6 m horizontally from the toe of the slope. The time of pile construction does affect the time to slope

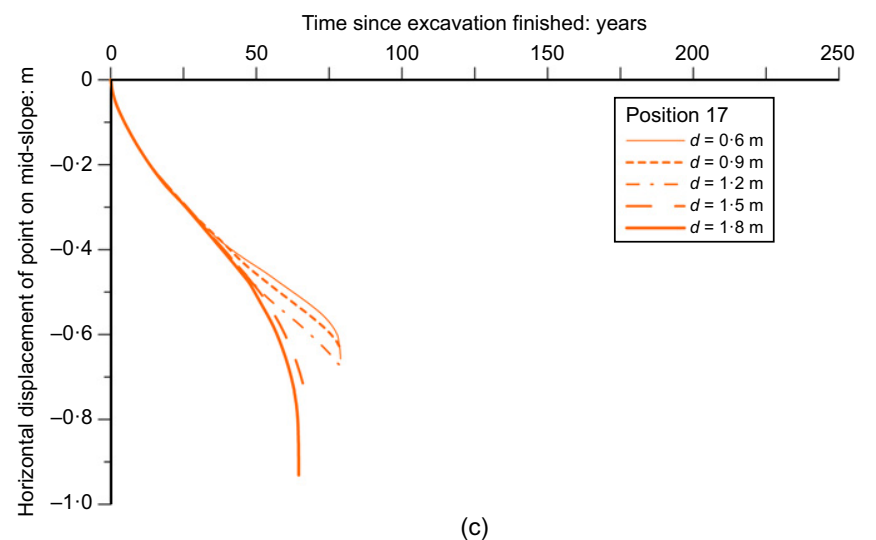

(c)

Fig. 12. Comparing the horizontal displacement of the mid-slope over time for analyses with varied pile diameters between $0 \cdot 6 \mathrm{~m}$ and $1 \cdot 8 \mathrm{~m}, 15 \mathrm{~m}$ long piles at three positions between the toe and crest of the slope 
failure, with values varying from $51 \cdot 65$ years to $142 \cdot 37$ years, Fig. 13. The greatest improvement in stability occurs when the pile is placed immediately after slope excavation. When the pile is placed 10 years after the slope excavation, there is still a large improvement in stability, while a pile placed 20 years after slope excavation almost doubles the lifetime of the slope prior to failure. A pile placed at 30 or 40 years, however, only increases slope stability by just over 10 years. These two analyses (see Figs 14(d) and 14(e)) have failure mechanisms with very similar patterns to the no-pile analysis (Fig. 14(f)). The accumulated plastic deviatoric contours for the 10 and 20 years pile construction show a large involvement of the pile, Figs 14(b) and 14(c), while the depth of the slip surface was also deeper for these two

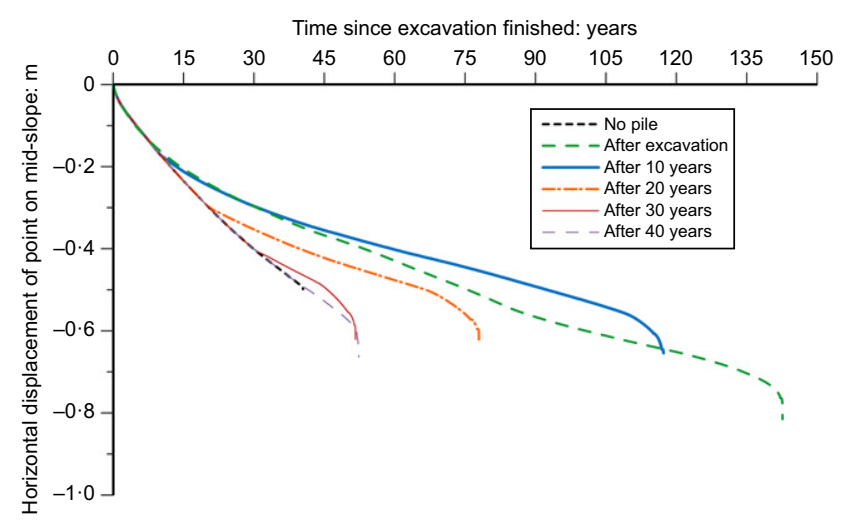

Fig. 13. Comparing the horizontal displacement of the mid-slope over time with $15 \mathrm{~m}$ long, $0.9 \mathrm{~m}$ diameter piles constructed in position 9 between the toe and crest of the slope after varied periods of consolidation

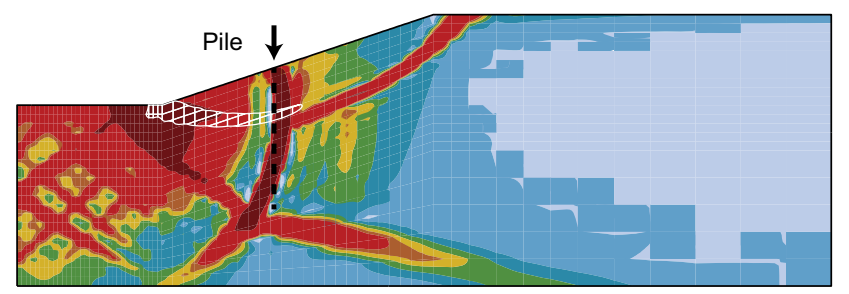

(a)

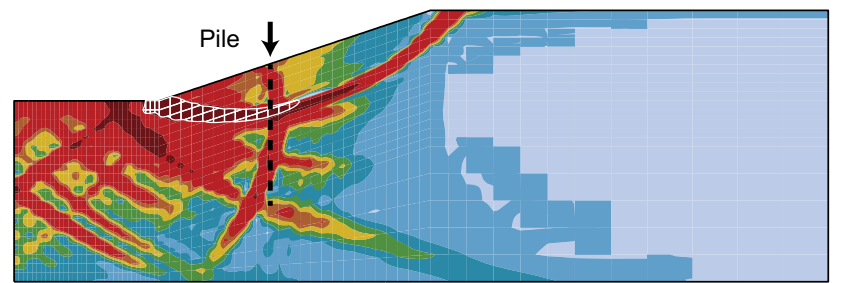

(c)

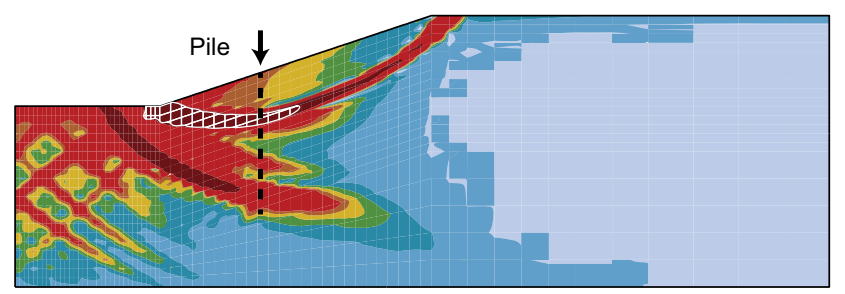

(e) analyses, as shown by the overlaid outline for the consolidation to failure analysis of the $20 \%$ strain contour of the critical surface. This zone corresponds to soil with a lower strength. When the pile is placed later, the areas of high strain concentration have already extended past the location where the pile will be constructed and cause the location of the critical slip surface to coincide with the consolidation analysis, Figs 14(d) and 14(e). There is still some modification of the slip surface behind the pile for the analysis with a pile constructed after 20 years, Fig. 14(c). This effect could be influenced by the strain-softening behaviour of the soil modelled. Once one area of soil has reached a strain that begins strain softening of the soil strength, this soil cannot sustain the same load and the excess loading is redistributed to the surrounding soil. This leads to the progression of a slip surface that may not occur in a non-softening soil. Once a strain-softening slip surface has begun forming upslope of where the pile will be constructed, the strain softening of the soil could encourage development of the slip surface even after construction of the pile interrupts soil movement.

The increase in time to failure is assessed by an analysis employing an incremental increase in time until slope failure, but it is not the only measure of slope stability. The variation of $\mathrm{FoS}$ with time was also examined for the analyses varying the time of placement of the pile, by conducting FoS analyses at distinct time instances during the consolidation period. This provides a comparison of relative improvement in stability after the same period of soil consolidation. The time of pile construction FoS results are compared with the corresponding FoS results for the no-pile analysis in Fig. 15. The values for the FoS show the same pattern of decreasing with increased period of consolidation as the no-pile analysis. The overall improvement in the FoS value caused by the pile is small, but reflects the improvement in time to slope failure. The difference between the FoS values for the no-pile analysis

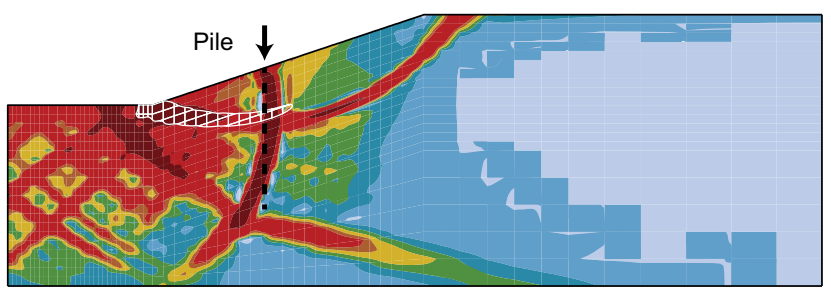

(b)

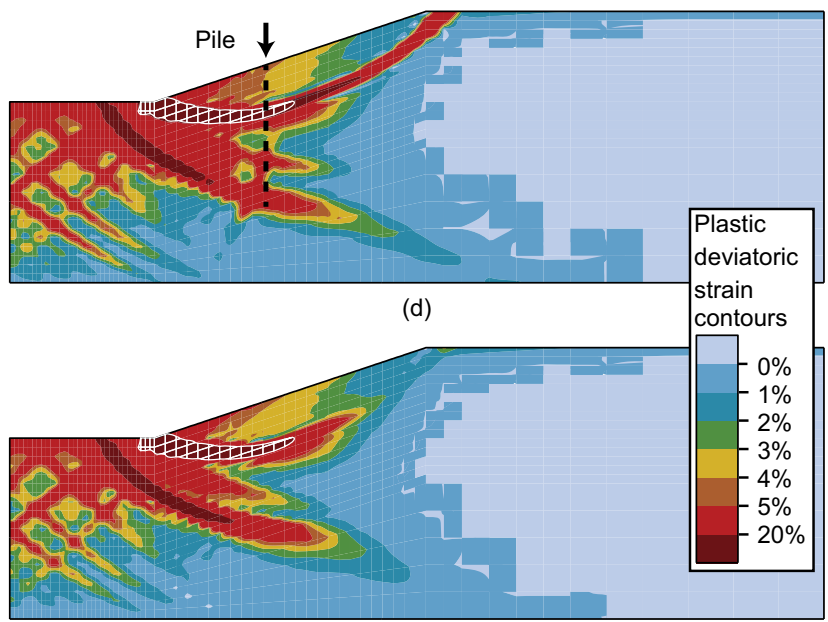

(f)

Fig. 14. Accumulated local plastic deviatoric strain contours for the final increment of the analyses that constructed a $15 \mathrm{~m}$ long, $0 \cdot 9 \mathrm{~m}$ dia. pile in position 9 between the crest and toe of the slope after varied periods of consolidation: (a) after excavation; (b) after 10 years' consolidation; (c) after 20 years' consolidation; (d) after 30 years' consolidation; (e) after 40 years' consolidation; (f) consolidation until failure after 40 years. A full-colour version of this figure can be found on the ICE Virtual Library (www.icevirtuallibrary.com) 


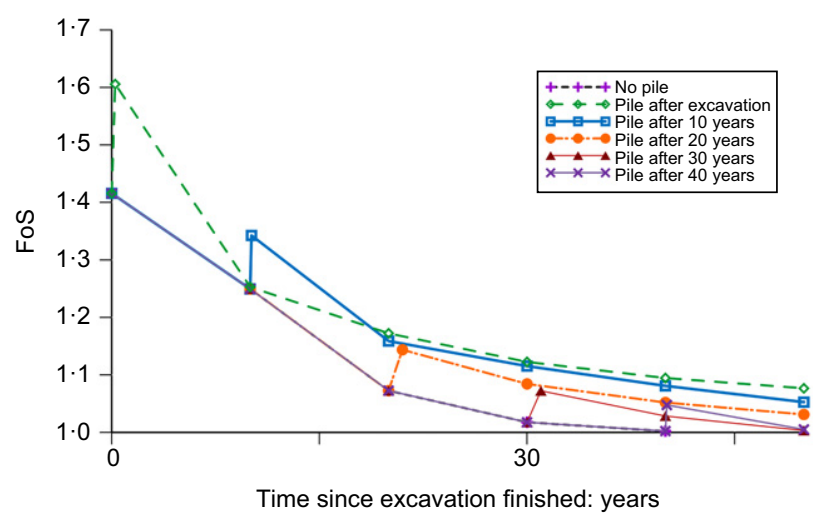

Fig. 15. The variation of the value for the FoS over time for analyses with a pile constructed after varying periods of consolidation

and each pile analysis is greatest immediately after pile construction. For the analyses with pile construction after 10 and after 40 years, the FoS value immediately after pile construction is higher than the FoS at the same period for a pile constructed 10 years earlier, Fig. 15. This initial jump implies a greater improvement in stability than is seen by the subsequent FoS analyses and the time to failure analysis. It is therefore perhaps misleading to use a single FoS value assessed immediately after pile construction, as the consolidation of soil and continued modelling of time affects the pile and soil interaction. The appropriate time to assess the FoS improvement provided by a pile requires careful consideration. It is perhaps best to assess this value at the end of the design life of the structure.

\section{CONCLUSIONS}

An extensive parametric study was undertaken to systematically examine the impact of pile position, dimensions (length and diameter) and time of pile construction on the stability of a cutting in London Clay, which was chosen as a representative strain-softening material. To avoid the mesh dependency seen in FE analyses involving strain localisation (e.g. Summersgill et al., 2017a, 2017b), a non-local strainsoftening model was employed. The analyses results show that the interaction of a vertical stabilisation pile and slope is complex, particularly in strain-softening materials where the developed failure mechanism evolves significantly with time. The results clearly show that construction of a pile does not provide a single stabilising action at the intersection with the critical slip surface of the unstabilised slope. Moreover, the pile is most effective in extending the stability of the slope when the failure mechanism is significantly altered by the presence of the pile. These findings challenge some of the current design procedures for these piles, which treat the pile only as an additional force or moment and simplify soil-pile interaction. An oversimplification during design could miss the critical failure mechanism or provide a conservative stabilisation solution.

Furthermore, the parametric study showed that the pile position and length have a large influence on the stabilising effect of the pile. The pile should be designed to interact with all potentially critical slip surfaces. The analyses demonstrated that for stiff clay excavated slopes the pile should be placed between the mid-slope and the toe of the slope, although not exactly at the toe of the slope. For the presented example of a $10 \mathrm{~m}$ high, 1 in 3 angled slope, a pile placed one third in from the toe of the slope should be more than $9 \mathrm{~m}$ long to provide a reasonable improvement in stability. It should be noted that the adopted slope dimensions in this study are such that a slope in a strain-softening material would fail during its design life (without piles) and are consistent with several cases observed in motorway and railway cuttings in the UK. Clearly, while the quantitative results are not portable to other cases, the qualitative conclusions are of general applicability.

The time of pile construction was found to be very influential on the contribution of the pile to slope stabilisation. Construction of a pile immediately after excavation of the slope simulates the construction of a new, overly steep slope with additional stabilisation to extend the design life of the slope. Construction of a pile after a period of consolidation is more representative of a system of stabilisation piles installed as a remedial measure. It was found that if the slip surface had developed beyond the pile location prior to pile construction, the pile did not significantly alter the existing strain distributions and the original failure mechanism persisted. This occurs as a result of the strain-softening behaviour of the soil encouraging the continued development of a slip surface once it has begun. The variation of the FoS value was also evaluated for the pile constructed at different times after slope failure. If the FoS was evaluated immediately after pile construction, it exaggerated the long-term contribution of the pile to slope stability, when compared to an FoS evaluated for the same analysis, but after a period of consolidation. This reduces the confidence in the use of a single FoS value to demonstrate the contribution of the pile to stabilisation.

The stabilisation pile analyses have demonstrated the importance of understanding the change in strain distribution due to the presence of the pile. Further factors to consider in slopes stabilised in strain-softening materials would include the pile spacing, stiffness and threedimensional analyses modelling arching between the piles. Without a robust understanding of these factors, a simplified method of analysis could provide misleading results.

\section{ACKNOWLEDGEMENTS}

This work was part of the $\mathrm{PhD}$ research of the first author at Imperial College London through an Industrial Cooperative Award in Science \& Technology (CASE) jointly funded by the Engineering and Physical Sciences Research Council (EPSRC) and Geotechnical Consulting Group LLP. This support is gratefully acknowledged.

\section{APPENDIX}

The figures included in this Appendix present data for all examined pile positions (see Figs 16-19).

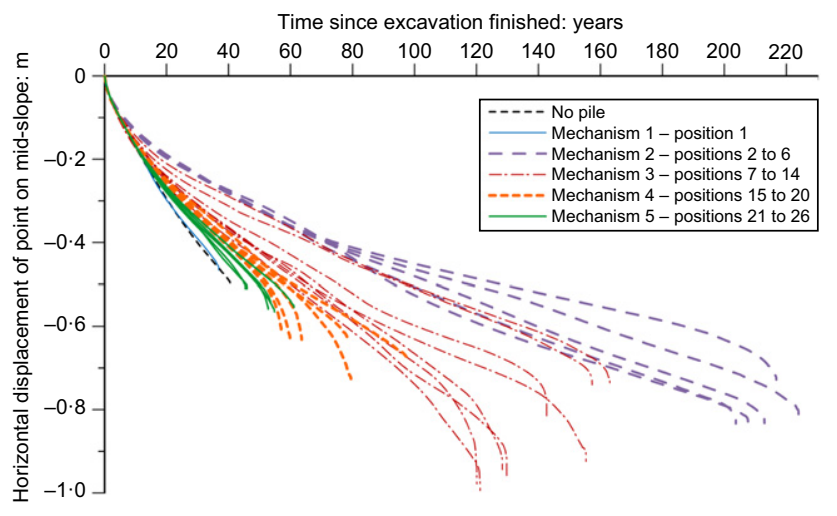

Fig. 16. Horizontal displacement variation of a mid-slope ground surface point over time for 26 analyses with $15 \mathrm{~m}$ long, $0 \cdot 9 \mathrm{~m}$ dia. piles in varied locations between the toe and crest of the slope 


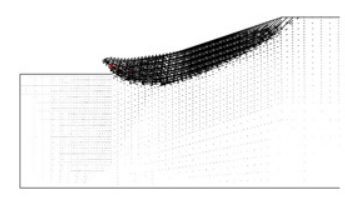

(a)
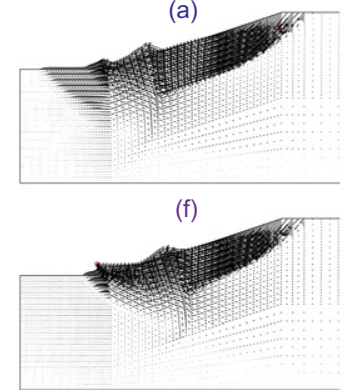

(k)

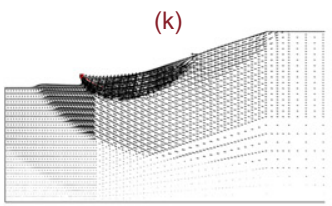

(p)

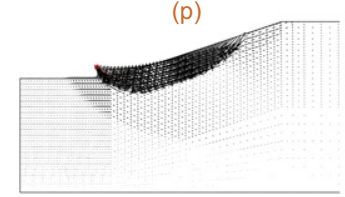

(u)

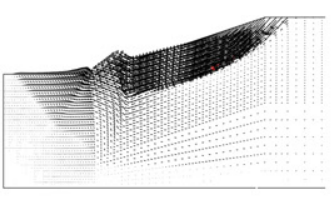

(b)
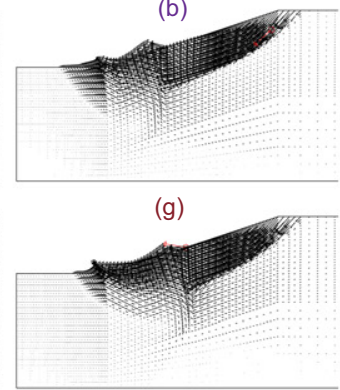

(I)
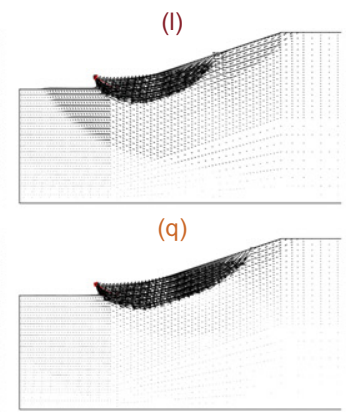

(v)

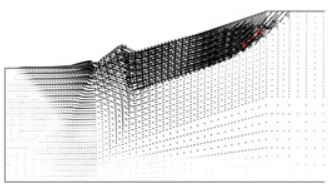

(c)

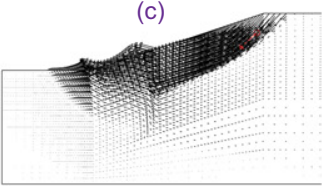

(h)

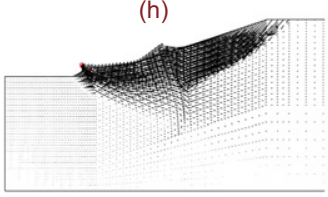

(m)
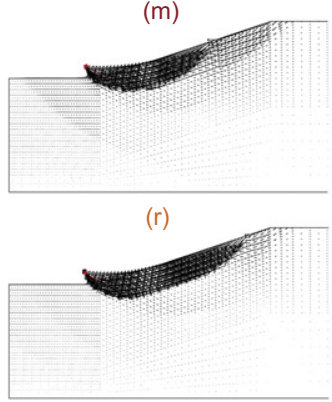

(w)

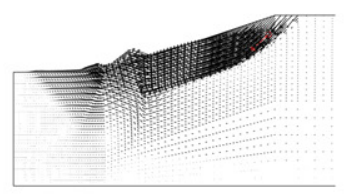

(d)

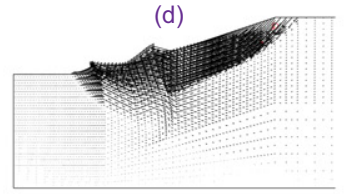

(i)
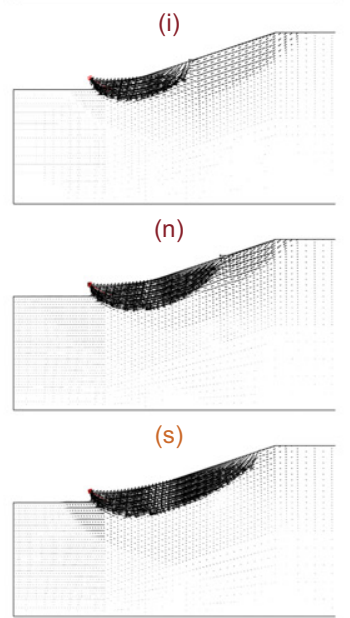

(x)

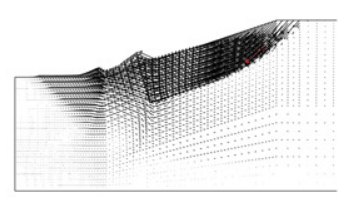

(e)

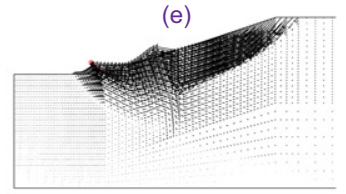

(j)
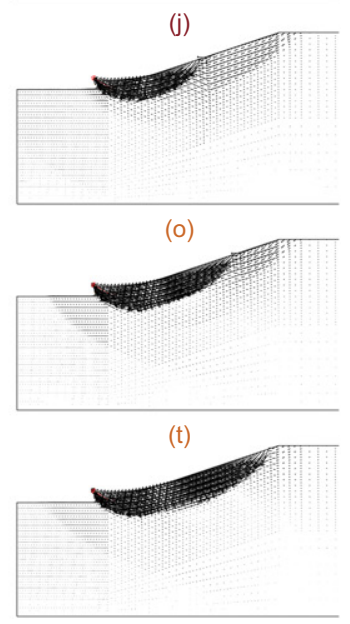

(y)

Fig. 17. Incremental displacement vectors for the final increment of the analysis, for the analyses with a pile in the first 25 positions of dimensions $15 \mathrm{~m}$ long, $0.9 \mathrm{~m}$ dia. piles in varied locations between the toe and crest of the slope: (a) $p=1, m=1 ;(b) p=2, m=2 ;(c) p=3, m=2 ;(d) p=4$, $m=2$; (e) $p=5, m=2$; (f) $p=6, m=2$; (g) $p=7, m=3$; (h) $p=8, m=3$; (i) $p=9, m=3$; (j) $p=10, m=3$; (k) $p=11, m=3$; (l) $p=12, m=3$; (m) $p=13, m=3 ;$ (n) $p=14, m=3 ;$ (o) $p=15, m=4 ;$ (p) $p=16, m=4 ;$ (q) $p=17, m=4 ;($ r) $p=18, m=4 ;(s) p=19, m=4 ;$ (t) $p=20, m=4 ;$ (u) $p=21, m=5$; (v) $p=22, m=5$; (w) $p=23, m=5$; (x) $p=24, m=5$; (y) $p=25, m=5$

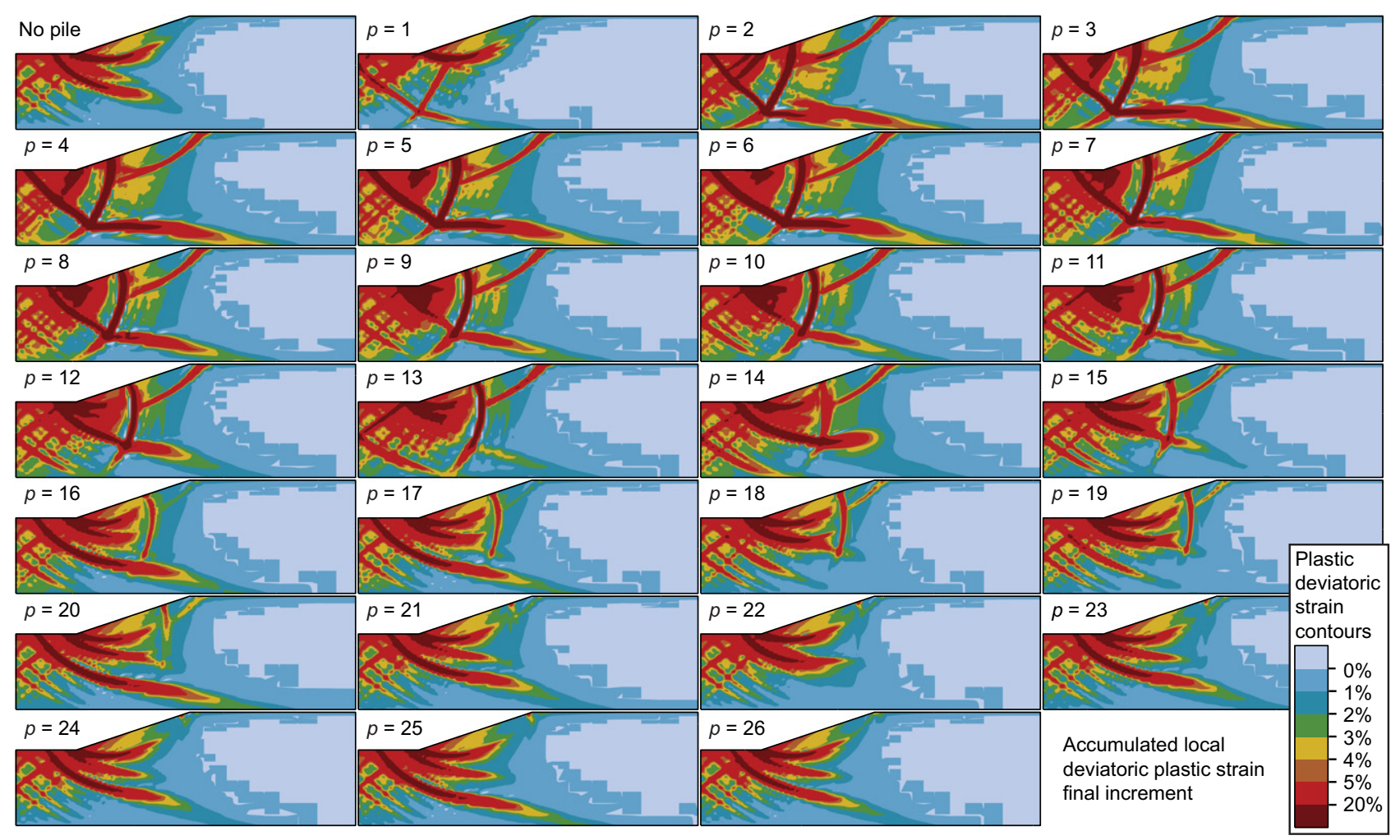

Fig. 18. Accumulated plastic deviatoric strain contours for the final increment of the analysis, for the pile in various positions between the toe and crest of the slope. The pile is $15 \mathrm{~m}$ long with a diameter of $0.9 \mathrm{~m}$. A full-colour version of this figure can be found on the ICE Virtual Library (www.icevirtuallibrary.com) 


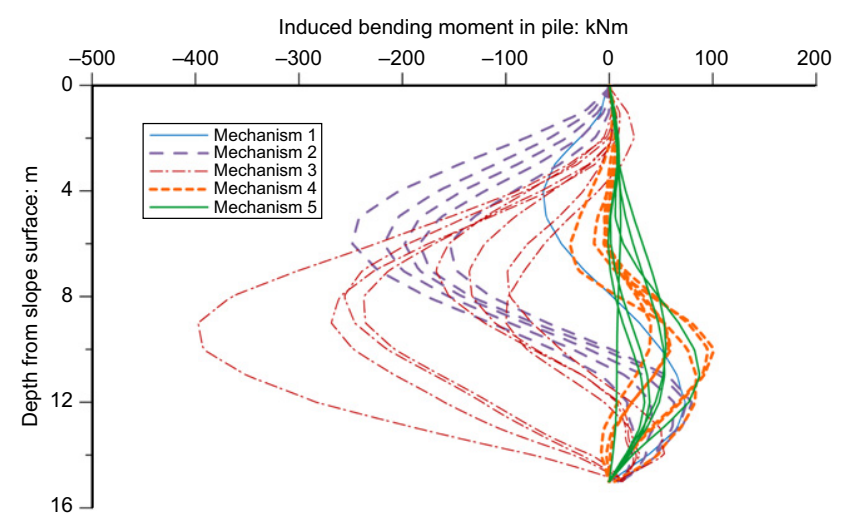

Fig. 19. The effect of pile position between the toe and crest of the slope on the bending moment induced in the $15 \mathrm{~m}$ long, $0.9 \mathrm{~m}$ dia. pile at the end of the analysis for all pile positions

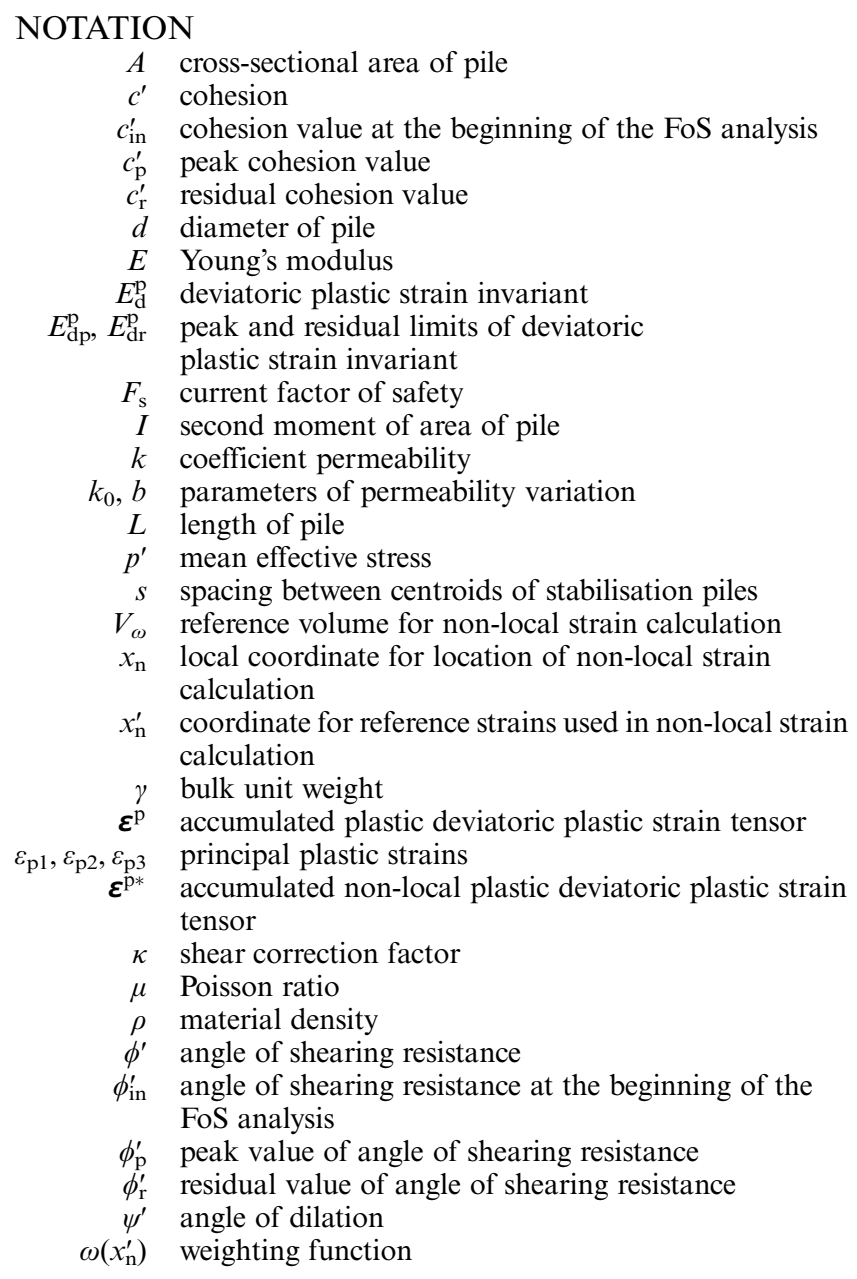

\section{REFERENCES}

Ausilio, E., Conte, E. \& Dente, G. (2001). Stability analysis of slopes reinforced with piles. Comput. Geotech. 28, No. 8, 591-611.

Baguelin, R., Frank, R. \& Said, Y. H. (1977). Theoretical study of lateral reaction mechanism of piles. Géotechnique 27, No. 3, 405-434, http://dx.doi.org/10.1680/geot.1977.27.3.405.

Bazant, Z. P. \& Jirasek, M. (2002). Nonlocal integral formulations of plasticity and damage: survey of progress. J. Engng Mech. 128, No. 11, 1119-1149.

Bazant, Z. P., Belytschko, T. B. \& Chang, T. P. (1984). Continuum model for strain softening. J. Engng Mech. 110, No. 12, $1666-1692$.
Cai, F. \& Ugai, K. (2000). Numerical analysis of the stability of a slope reinforced with piles. Soils Found. 40, No. 1, 73-84.

Carder, D. (2005). Design guidance on the use of a row of spaced piles to stabilise clay highway slopes, Report TRL632. Crowthorne, UK: Transport Research Laboratory (TRL).

Durrani, I. K. (2006). Numerical modelling of discrete pile rows to stabilise slopes. $\mathrm{PhD}$ thesis, Nottingham University, Nottingham, UK.

Ellis, E. A. \& O'Brien, A. S. (2007). Effect of height on delayed collapse of cuttings in stiff clay. Proc. Instn Civ. Engrs - Geotech. Engng 160, No. 2, 73-84, http://dx.doi.org/10.1680/geng.2007. 160.2.73.

Ellis, E. A., Durrani, I. K. \& Reddish, D. J. (2010). Numerical modelling of discrete pile rows for slope stability and generic guidance for design. Géotechnique 60, No. 3, 185-195, http:// dx.doi.org/10.1680/geot.7.00090.

Eringen, A. C. (1981). On nonlocal plasticity. Int. J. Engng Sci. 19, No. $12,1461-1474$.

Galavi, V. \& Schweiger, H. F. (2010). Nonlocal multilaminate model for strain softening analysis. Int. J. Geomech. 10, No. 1, 30-44.

Galli, A. \& di Prisco, C. (2013). Displacement-based design procedure for slope stabilizing piles. Can. Geotech. J. 50, No. 1, $41-53$.

Georgiadis, K. \& Georgiadis, M. (2010). Undrained lateral pile response in sloping ground. J. Geotech. Geoenviron. Engng 136, No. $11,1489-1500$.

Hassiotis, S., Chameau, J. L. \& Gunaratne, M. (1997). Design method for stabilization of slopes with piles. J. Geotech. Geoenviron. Engng 123, No. 4, 314-323.

Hayward, T., Lees, A., Powrie, W., Richards, D. J. \& Smethurst, J. (2000). Centrifuge modelling of a cutting slope stabilised by discrete piles, Report number: TRL471. Crowthorne, UK: Transport Research Laboratory (TRL).

Higgins, W., Vasquez, C., Basu, D. \& Griffiths, D. (2013). Elastic solutions for laterally loaded piles. J. Geotech. Geoenviron. Engng 139, No. 7, 1096-1103.

Hight, D. W., Gasparre, A., Nishimura, S., Minh, N. A., Jardine, R. J. \& Coop, M. R. (2007). Characteristics of the London clay from the Terminal 5 site at Heathrow Airport. Géotechnique 57, No. 1, 3-18, http://dx.doi.org/10.1680/geot.2007.57.1.3.

Ito, T. \& Matsui, T. (1975). Methods to estimate lateral force acting on stabilizing piles. Soils Found. 15, No. 4, 43-59.

Kourkoulis, R., Gelagoti, F., Anastasopoulos, I. \& Gazetas, G. (2011). Slope stabilizing piles and pile-groups: parametric study and design insights. J. Geotech. Geoenviron. Engng 137, No. 7, 663-677.

Kourkoulis, R., Gelagoti, F., Anastasopoulos, I. \& Gazetas, G. (2012). Hybrid method for analysis and design of slope stabilizing piles. J. Geotech. Geoenviron. Engng 138, No. 1, 1-14.

Kovacevic, N. (1994). Numerical analysis of rockfill dams, cuts slopes and road embankments. PhD thesis, Imperial College London, London, UK.

Lee, Y. S. (2015). Numerical modelling of non-softening material cut slopes with piles for stabilisation. MSc thesis, Imperial College London, London, UK.

Lee, C. Y., Hull, T. S. \& Poulos, H. G. (1995). Simplified pile-slope stability analysis. Comput. Geotech. 17, No. 1, 1-16.

Potts, D. M. \& Zdravković, L. (1999). Finite element analysis in geotechnical engineering: theory. London, UK: Thomas Telford.

Potts, D. M. \& Zdravković, L. (2001). Finite element analysis in geotechnical engineering: application. London, UK: Thomas Telford.

Potts, D. M. \& Zdravković, L. (2012). Accounting for partial material factors in numerical analysis. Géotechnique 62, No. 12, 1053-1065, http://dx.doi.org/10.1680/geot.11.P.057.

Potts, D. M., Dounias, G. T. \& Vaughan, P. R. (1990). Finite element analysis of progressive failure of Carsington embankment. Géotechnique 40, No. 1, 79-101, http://dx.doi.org/10.1680/ geot.1990.40.1.79.

Potts, D. M., Kovacevic, N. \& Vaughan, P. R. (1997). Delayed collapse of cut slopes in stiff clay. Géotechnique 47, No. 5, 953-982, http://dx.doi.org/10.1680/geot.1997.47.5.953.

Smethurst, J. A. \& Powrie, W. (2007). Monitoring and analysis of the bending behaviour of discrete piles used to stabilise a railway embankment. Géotechnique 57, No. 8, 663-677, http://dx.doi. org/10.1680/geot.2007.57.8.663. 
Summersgill, F. C. (2015). Numerical modelling of stiff clay cut slopes with nonlocal strain regularisation. $\mathrm{PhD}$ thesis, Imperial College London, London, UK.

Summersgill, F., Kontoe, S. \& Potts, D. (2017a). Critical assessment of nonlocal strain-softening methods in biaxial compression. Int. J. Geomech. (ASCE) 17, No. 7, 04017006.

Summersgill, F. C., Kontoe, S. \& Potts, D. M. (2017b). On the use of nonlocal regularisation in slope stability problems. Comput. Geotech. 82, 187-200.
Vaughan, P. R. (1994). Assumption, prediction and reality in geotechnical engineering. Géotechnique 44, No. 4, 573-609, http://dx.doi.org/10.1680/geot.1994.44.4.573.

Vaughan, P. R. \& Walbancke, H. J. (1973). Pore pressure changes and the delayed failure of cutting slopes in over-consolidated clay. Géotechnique 23, No. 4, 531-539, http://dx.doi.org/ 10.1680/geot.1973.23.4.531.

Zhang, G. \& Wang, L. (2010). Stability analysis of strain-softening slope reinforced with stabilizing piles. J. Geotech. Geoenviron. Engng 136, No. 11. 